\title{
Estudo dos fármacos selecionados em ensaios clínicos na terapia farmacológica da COVID-19
}

\author{
Study of selected drugs in clinical trials in the pharmacological therapy of COVID-19 \\ Estudio de fármacos seleccionados en ensayos clínicos en la terapia farmacológica de la COVID-19
}

Recebido: 07/12/2021 | Revisado: 14/12/2021 | Aceito: 20/12/2021 | Publicado: 03/01/2022

Tatiana Aparecida Furuzawa

ORCID: https://orcid.org/0000-0003-4421-3035

Universidade Estadual de Maringá, Brasil

E-mail: taticafuruzawa@gmail.com

Gabriel Fernando Esteves Cardia

ORCID: https://orcid.org/0000-0003-3781-7498

Universidade Estadual de Maringá, Brasil E-mail: g_cardia@hotmail.com

Mariana Vessoni Iwaki

ORCID: https://orcid.org/0000-0001-6127-197X

Universidade Estadual de Maringá, Brasil

E-mail: ra107043@uem.br

Edivaldo Cremer

ORCID: https://orcid.org/0000-0001-8604-1556

Universidade Estadual do Norte do Paraná, Brasil

E-mail: edivaldocremer@uenp.edu.br

Ricardo Alexandre Spironello

ORCID: https://orcid.org/0000-0002-7068-7931

Universidade Estadual de Maringá, Brasil E-mail: ricardospironello@gmail.com

Francielli Maria de Souza Silva Comar

ORCID: https://orcid.org/0000-0001-6840-9345

Universidade Estadual de Maringá, Brasil

E-mail: franciellimss@gmail.com

Roberto Kenji Nakamura Cuman

ORCID: https://orcid.org/0000-0002-4906-887X

Universidade Estadual de Maringá, Brasil

E-mail: rkncuman1@gmail.com

\begin{abstract}
Resumo
A COVID-19 é uma infecção respiratória aguda causada pelo coronavírus SARS-CoV-2, potencialmente grave, de elevada transmissibilidade e de distribuição global. A busca por drogas que apresentam atividade sobre o SARS-CoV2 é um desafio constante sem precedentes na validação de medicamentos eficazes no tratamento de pacientes acometidos pela COVID-19. Objetivo: Esta revisão integrativa teve como objetivo avaliar trabalhos na literatura científica, envolvendo ensaios clínicos que avaliam a eficácia de drogas já disponíveis no mercado para provável utilização no tratamento da COVID-19. Metodologia: A pesquisa foi realizada no período de abril de 2020 até junho de 2021 nas bases de dados PubMed, SciElo e Lilacs, utilizando os Descritores em Ciências da Saúde (DeCS) “COVID-19”, "SARS-CoV-2", "Medicamentos", "Ensaio Clínico", "Terapêutica". Os critérios para inclusão dos artigos na pesquisa foram os que apresentaram resumo e texto disponibilizados na íntegra eletronicamente, escritos em inglês, português e espanhol publicados no período de abril de 2020 a junho de 2021, em periódicos científicos e que avaliaram a eficácia de prováveis fármacos no tratamento da COVID-19 e ensaios clínicos em pacientes hospitalizados portadores da doença. Foram excluídos os artigos que não abordaram, em conjunto, o tema do estudo, artigos duplicados nas bases de dados, artigos de revisão, artigos baseados em ensaios in vitro / in vivo em animais, artigos baseados em medicina tradicional, estudos do tipo editorial e também os artigos reflexivos. Resultados: Dos 210 artigos identificados, 132 foram excluídos por não atenderem os critérios de inclusão, sendo selecionados para este estudo 78 artigos que objetivaram o estudo da eficácia de fármacos em ensaios clínicos internacionais. Destes, 67 estavam indexados na base de dados PubMed; 6 pelo SciELO; e, 5 na Lilacs. Foram analisados 49 fármacos, classificados em 22 classes farmacológicas. As principais classes de fármacos em estudos foram: antivirais de ação direta em monoterapia, 8 (16,32\%); imunomoduladores, 7 (14,28\%); imunomoduladores + associações, 2 (4,08\%); e, imunoestimulantes + associações, 2 (4,08\%). Conclusão: Os fármacos e suas associações em estudo não apresentaram eficácia terapêutica específica para o tratamento da COVID-19; porém, os ensaios clínicos indicaram melhora dos
\end{abstract}


sintomas clínicos dos pacientes e do tempo de internamento hospitalar. Entretanto, alguns fármacos apresentaram significativas reações adversas, interferindo diretamente na segurança dos pacientes.

Palavras-chave: COVID-19; SARS-CoV-2; Medicamentos; Ensaio Clínico; Terapêutica.

\begin{abstract}
COVID-19 is an acute respiratory infection caused by the potentially severe, highly transmissible, globally distributed SARS-CoV-2 coronavirus. The search for drugs that have activity on SARS-CoV-2 is a constant challenge without precedent in the validation of effective drugs in the treatment of patients affected by COVID-19. Objective: This integrative review aimed to assess studies in the scientific literature, involving clinical trials that evaluate the efficacy of drugs already available on the market for probable use in the treatment of COVID-19. Methodology: The search was conducted from April 2020 to June 2021 in the PubMed, SciElo and Lilacs databases, using the Health Science Descriptors (DeCS) "COVID-19", "SARS-CoV-2", "Drugs", "Trials Clinicals", "Treatments". The criteria for inclusion of articles in the search were those with abstract and text available in full electronically, written in English, Portuguese, and Spanish, published from April 2020 to June 2021, in scientific journals, and that evaluated the efficacy of probable drugs in the treatment of COVID-19 and clinical trials in hospitalized patients with the disease. Articles that did not jointly address the topic of the study, duplicate articles in the databases, review articles, articles based on in vitro / in vivo animal trials, articles based on traditional medicine, editorial type studies and also the reflexive articles were excluded. Results: Of the 210 articles identified, 132 were excluded for not meeting the inclusion criteria, and 78 articles that aimed to study drug efficacy in international clinical trials were selected for this study. Of these, 67 were in PubMed, 6 in SciELO, and 5 in Lilacs. A total of 49 drugs were analyzed, classified into 22 pharmacological classes. The main classes of drugs in studies were: direct acting antivirals in monotherapy, 8 (16.32\%); immunomodulators, 7 (14.28\%); immunomodulators + associations, 2 (4.08\%); and immunostimulants + associations, $2(4.08 \%)$. Conclusion: The drugs and their associations under study did not show specific therapeutic efficacy for the treatment of COVID-19; however, clinical trials indicated improvement in patients' clinical symptoms and hospital length of stay. However, some drugs showed significant adverse reactions, directly interfering with patient safety.
\end{abstract}

Keywords: COVID-19; SARS-CoV-2; Drugs; Clinical Trial; Therapeutics.

\title{
Resumen
}

La COVID-19 es una infección respiratoria aguda causada por el coronavirus SARS-CoV-2, potencialmente grave, altamente transmisible y de distribución mundial. La búsqueda de fármacos con actividad contra el SARS-CoV-2 es un reto sin precedentes y constante en la validación de fármacos eficaces para el tratamiento de pacientes con COVID-19. Objetivo: Esta revisión integradora tuvo como objetivo evaluar los estudios en la literatura científica, con ensayos clínicos que evalúan la eficacia de los medicamentos ya disponibles en el mercado para su probable uso en el tratamiento de la COVID-19. Metodología: La investigación se llevó a cabo en el período de abril de 2020 a junio de 2021 en las bases de datos PubMed, SciElo y Lilacs, utilizando los buscadores de ciencias de la salud (DeCS) "COVID-19", "SARS-CoV-2", "Medicamentos", "Ensayo Clínico", "Terapéutica". Los criterios de inclusión de los artículos en la búsqueda fueron aquellos con resumen y texto disponible en formato electrónico completo, escritos en inglés, portugués y español, publicados entre abril de 2020 y junio de 2021, en revistas científicas y que evaluaran la eficacia de probables fármacos en el tratamiento de la COVID-19 y ensayos clínicos en pacientes hospitalizados con la enfermedad. Se excluyeron los artículos que no abordaban conjuntamente el tema del estudio, los artículos duplicados en las bases de datos, los artículos de revisión, los artículos basados en ensayos animales in vitro / in vivo, los artículos basados en la medicina tradicional, los estudios de tipo editorial y también los artículos reflexivos. Resultados: De los 210 artículos identificados, se excluyeron 132 por no cumplir los criterios de inclusión, y se seleccionaron para este estudio 78 artículos que pretendían estudiar la eficacia de los medicamentos en ensayos clínicos internacionales. De ellos, 67 en la base de datos PubMed; 6 por SciELO; y, 5 en Lilacs. Se analizaron 49 medicamentos, clasificados en 22 clases farmacológicas. Las principales clases de medicamentos en los estudios fueron: antivirales de acción directa en monoterapia, 8 (16,32\%); inmunomoduladores, 7 (14,28\%); inmunomoduladores + asociaciones, 2 (4,08\%); e, inmunoestimulantes + asociaciones, 2 (4,08\%). Conclusión: Los fármacos y sus asociaciones en estudio no presentan una eficacia terapéutica específica para el tratamiento de la COVID-19; sin embargo, los ensayos clínicos indican una mejora de los síntomas clínicos de los pacientes y del tiempo de internamiento. Sin embargo, algunos medicamentos mostraron reacciones adversas significativas, interfiriendo directamente con la seguridad del paciente.

Palabras clave: COVID-19; SARS-CoV-2; Medicamentos; Ensayo Clínico; Terapéutica.

\section{Introdução}

Em dezembro de 2019, uma epidemia de infecção viral aguda surgiu em Wuhan, uma cidade chinesa de 11 milhões de habitantes, na província de Hubei, que foi denominada pela Organização Mundial da Saúde (OMS) de COVID-19 (Coronavirus Disease). Foi identificado como agente causador da doença, o vírus SARS-CoV-2 (Severe Acute Respiratory 
Syndrome Coronavirus 2), devido à proximidade genômica filogenética com o anteriormente conhecido SARS-CoV, vírus causador de uma epidemia viral em 2002 (Lu et al., 2020; Yuen et al.,2020).

A COVID-19 foi considerada uma pandemia pela OMS em 11 de março de 2020 (Organização Pan-Americana da Saúde [OPAS], 2020), devido a sua alta transmissibilidade, com uma taxa de incidência de 83\% (Chan et al., 2020) e está notificada a possibilidade de transmissão assintomática (Bai et al., 2020).

O SARS-CoV-2 propaga-se por meio de gotículas de saliva, secreções respiratórias e contato direto com superfícies contaminadas. A infecção ocorre quando o vírus adentra as membranas mucosas, especialmente a nasal e da laringe e se instala nos pulmões, causando sintomas iniciais mais comuns como febre e tosse. Estima-se que a infecção tenha um período médio de incubação de 6,4 dias (Lai et al., 2020). No início da manifestação dos sintomas, pode ocorrer leucopenia com linfopenia e em aproximadamente de 7 a 14 dias, ocorre o aumento dos fatores inflamatórios, o que leva ao agravo da doença (Huang et al., 2020).

A ativação imunológica descontrolada que ocorre em pacientes graves, conhecida como tempestade de citocinas, é uma resposta imunológica excessiva, tanto local, como sistêmica, com função pró- inflamatória (Huang et al., 2020). Esse processo provoca o aumento das interleucinas, com predominância de IL-6, IL-1 $\beta$, IL-8, TNF- $\alpha$ e interferon- $\gamma$, dentre outras e pode ser o grande marcador de prognóstico da gravidade do quadro infeccioso da doença porque os pacientes apresentando as formas leves e moderadas não apresentam esta resposta. No entanto, o aumento do nível de citocinas pró- inflamatórias tem sido detectado em grande parte dos pacientes graves, o que pode provocar uma hiperativação do sistema imunológico, desencadeando a Síndrome Respiratória Aguda Grave (SARS) ou falência múltipla de órgãos, que pode levar a deterioração fisiológica e morte (Simkin et al., 2021, Dhar, 2021).

Uma característica da infecção por SARS-CoV-2 é que indivíduos assintomáticos podem transmitir o vírus, de forma silenciosa. Todavia, é na fase sintomática que ocorre maior potencial de disseminação do mesmo (Hu et al., 2020).

Alguns indivíduos podem apresentar sintomas leves, que se iniciam gradualmente, como dores pelo corpo, congestão nasal, dor de cabeça, conjuntivite, dor de garganta, diarreia, perda de paladar ou olfato, erupção cutânea ou descoloração dos dedos das mãos ou dos pés. A maioria das pessoas (cerca de 80\%) se recupera da doença sem necessidade de tratamento hospitalar. Uma em cada seis pessoas infectadas por COVID-19 apresenta o quadro grave da doença e desenvolve dificuldade de respirar. As pessoas idosas e as que possuem comorbidades, como hipertensão, cardiopatias, pneumopatias, diabetes ou doenças imunossupressoras, apresentam maior risco de ficarem gravemente doentes. No entanto, qualquer pessoa pode contrair o vírus (OPAS, 2021a).

O controle da tempestade de citocinas nos estágios iniciais, por meio da redução da carga viral e controle das repostas inflamatórias por meio de imunomoduladores e imunossupressores, pode aumentar a taxa de sucesso na terapêutica e reduzir a taxa de mortalidade. Novas estratégias terapêuticas também foram estudadas, como os antivirais e associações, os antirreumáticos, o plasma convalescente e muitas outras (Ye et al., 2020).

De acordo com os dados do Painel do Coronavírus, mundialmente, até 30 de junho de 2021, foram confirmados 179.864 .792 casos da doença, incluindo 3.726 .466 mortes notificadas. Até 06 de setembro de 2021, um total de 5.352.927.296 doses diferentes disponíveis de vacina contra a COVID-19 foram administradas (WHO, 2021a).

As vacinas contra a COVID-19 foram desenvolvidas em uma velocidade sem precedentes. Os estudos comprovam a alto nível de eficácia e segurança de diferentes tipos de vacina, desenvolvidas a partir de tecnologias já existentes e de novas tecnologias, que representam inovações importantes para o futuro tratamento de várias doenças.

Apesar de serem produzidas por tecnologias diferentes, todas têm por objetivo induzir a resposta imunológica do organismo, fazendo com que haja produção de defesas contra o vírus da SARS-CoV-2 (OMS, 2021a). 
Pesquisas relacionadas ao impacto das vacinas sobre a transmissão ou disseminação viral contra a COVID-19 ainda estão em andamento. Portanto, é necessário manter e reforçar as medidas de vigilância sanitária que funcionam, como a utilização de máscaras, distanciamento físico, lavagem frequente das mãos, etiqueta respiratória e da tosse, afastamento de aglomerações e boa ventilação em espaços fechados (Aquino et al., 2020).

No Brasil, a ANVISA (Agência Reguladora, sob a forma de autarquia de regime especial, vinculada ao Ministério da Saúde), está presente em todo o território nacional por meio das coordenações de portos, aeroportos, fronteiras e recintos alfandegados). Este mesmo órgão, autorizou o uso de cinco medicamentos em caráter emergencial: o antiviral Remdesivir e os anticorpos monoclonais REGN-CoV-2 (associação dos anticorpos monoclonais Casirivimabe e Imdevimabe), a associação de Banlanivimabe e Etesevimabe; Regdanvimabe e Sotrovimabe. Foi aprovada também a nova indicação terapêutica do antirreumático Baracitinibe para COVID-19 (ANVISA, 2021a).

Diversas drogas já conhecidas por seus mecanismos de ação estão sendo utilizadas de forma off label (reposicionamento de fármacos) (Cohen, 2020).

\section{Metodologia}

Este estudo trata-se de uma revisão integrativa de literatura sobre a avaliação da eficácia de fármacos e suas associações selecionados em ensaios clínicos com provável aplicação no tratamento da COVID-19.

A pesquisa seguiu as etapas: definição do tema, elaboração da pergunta norteadora, estabelecimento de critérios de busca ou amostragem na literatura, definição das informações extraídas dos artigos (coleta de dados), análise crítica dos artigos incluídos, discussão e apresentação dos resultados.

Para nortear esta revisão, elaborou-se a seguinte questão: Quais são os fármacos ou associações de fármacos selecionados em ensaios clínicos com potencial eficácia no tratamento da COVID-19?

O levantamento na literatura dos trabalhos foi realizado no período de abril de 2020 até junho de 2021 nas bases de dados: serviço da U. S. National Library of Medicine - NLM (PubMed), Scientific Electronic Library Online (SciELO), Literatura Latino-Americana e do Caribe em Ciências da Saúde (Lilacs), utilizando os descritores encontrados na Biblioteca Virtual em Saúde (BVS): COVID-19; SARS-CoV-2; Medicamentos; Ensaio Clínico; Terapêutica.

Foram utilizados como critérios de inclusão artigos disponibilizados na íntegra, de forma eletrônica, escritos em inglês, português e espanhol, publicados no período de abril de 2020 até junho de 2021 em periódicos científicos selecionados, objetivando avaliar a eficácia dos prováveis fármacos no tratamento da COVID-19 e também aqueles baseados em ensaios clínicos, relatos de casos e estudos multicêntricos em pacientes acometidos pela doença.

Foram excluídos do estudo, trabalhos que não abordaram, em conjunto, o tema do estudo, aspectos da terapêutica farmacológica de drogas, os duplicados nas bases de dados, artigos de revisão, artigos baseados em ensaios in vitro / in vivo, em animais e os baseados em medicina tradicional, estudos do tipo editorial e estudos reflexivos.

Os fármacos selecionados nos ensaios clínicos encontrados nas pesquisas, foram classificados segundo a ATC 2021 (Anatomical Therapeutical Chemical Classification System).

\section{Resultados e Discussão}

Foram identificados 210 artigos nas bases de dados, sendo excluídos 132 por não abordarem o tema do estudo, conforme os critérios estabelecidos na revisão. Conforme apresentado na Figura 1, foram selecionados para este estudo 78 artigos que objetivaram o estudo dos fármacos ou associações de fármacos selecionados em ensaios clínicos com potencial utilização no tratamento da COVID-19. Destes, 61 foram em monoterapia encontrados utilizando a base de dados PubMed; 6 pelo SciELO; e, 5 na Lilacs. 
Figura 1 - Fluxograma da seleção de artigos.

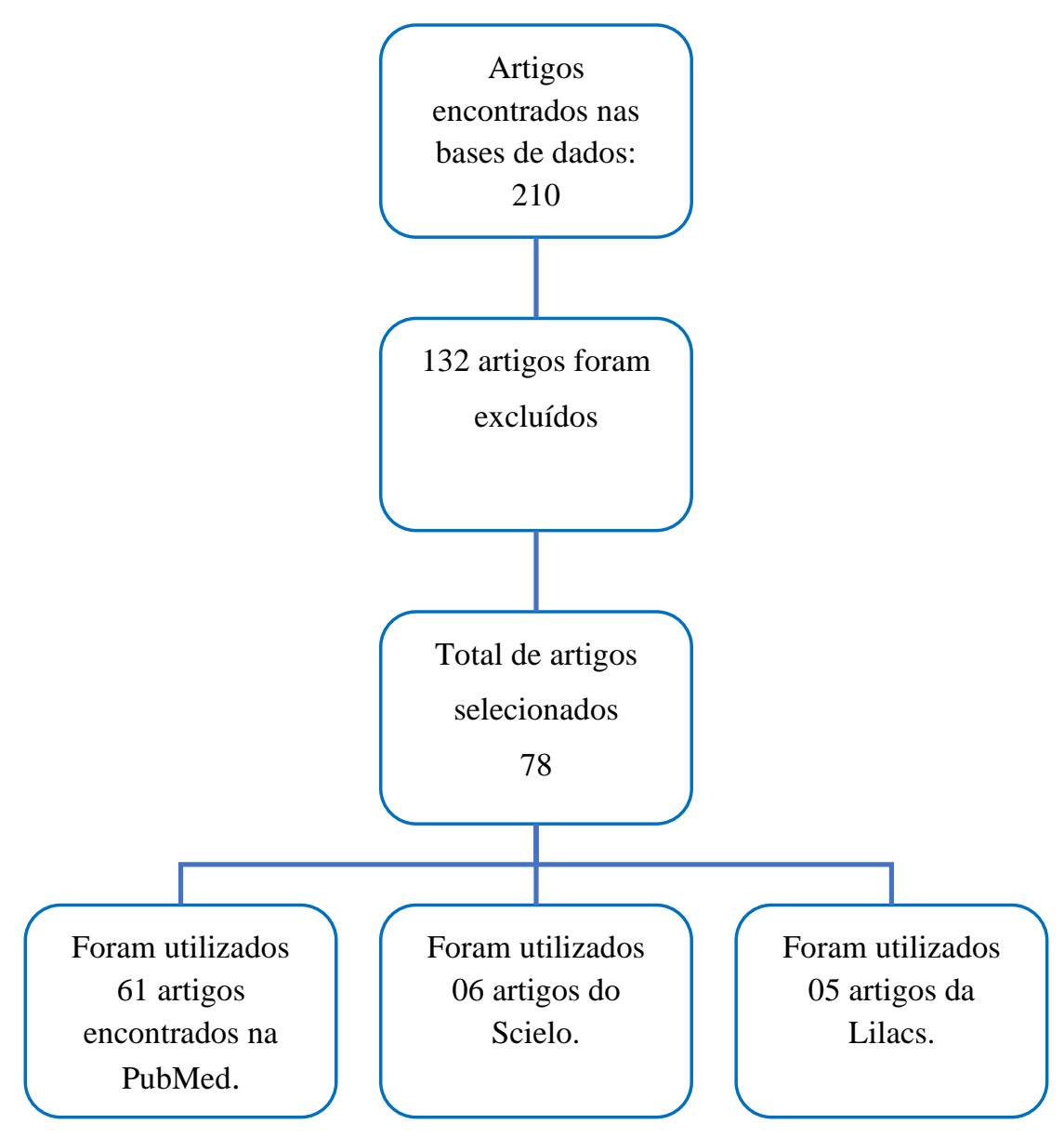

Fonte: Furuzawa, et al. (2021).

Nos ensaios clínicos foram estudados 45 fármacos em monoterapia ou em associações, classificados segundo a ATC em 18 classes farmacológicas distintas. No Gráfico 1 estão apresentadas as principais classes de fármacos em estudo e suas associações: antivirais em monoterapia, 9 (18,3\%); imunomoduladores, 7 (14,6\%); antivirais em associações, 5 (10,2\%); antibacterianos de uso sistêmico, 4 (8,16); e, antimaláricos, 4 (8,16\%). 
Research, Society and Development, v. 11, n. 1, e11611124445, 2021

(CC BY 4.0) | ISSN 2525-3409 | DOI: http://dx.doi.org/10.33448/rsd-v11i1.24445

Gráfico 1. Número e porcentagem de classes farmacológicas e associações estudadas

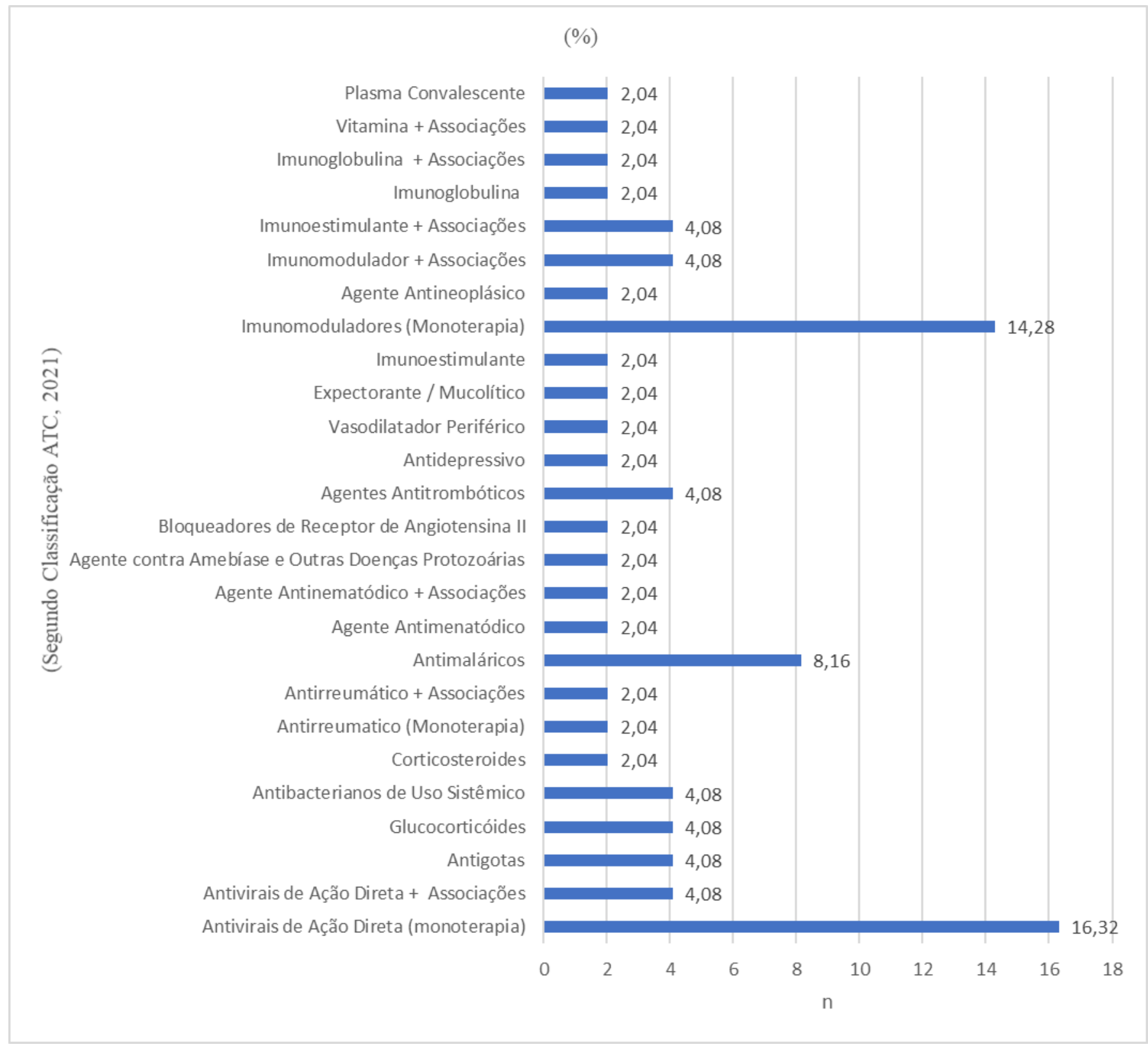

Fonte: Furuzawa et al. (2021).

Não foi demonstrada eficácia terapêutica específica para o tratamento da COVID-19 para os fármacos avaliados; porém, os ensaios clínicos indicaram redução da carga viral, melhora dos sintomas clínicos dos pacientes, redução do tempo de hospitalização e da taxa de mortalidade. Alguns fármacos apresentaram reações adversas significativas, interferindo diretamente na segurança dos pacientes quanto ao uso destes medicamentos na COVID-19. Na Tabela 1 estão apresentados os fármacos e suas associações, classificados de acordo com a ATC 2021, referências bibliográficas, tipos de estudos e seus desfechos. 
Tabela 1 - Tipos de Estudos e Desfechos.

\begin{tabular}{|c|c|c|c|c|}
\hline $\begin{array}{l}\text { Classes } \\
\text { Farmacológicas } \\
\text { (Segundo ATC, } \\
\text { 2021) } \\
\text { (Código) } \\
\end{array}$ & Fármacos & Referências Ano & $\begin{array}{l}\text { Tipo de } \\
\text { Estudo }\end{array}$ & Desfecho \\
\hline & Oseltamivir & Chiba (2021) & $\begin{array}{l}\text { Relato de } \\
\text { caso }\end{array}$ & Efetividade na redução dos sintomas clínicos. \\
\hline & Molnupiravir * & Fischer et al. (2021) & $\begin{array}{l}\text { Ensaio } \\
\text { clínico }\end{array}$ & $\begin{array}{l}\text { Alta efetividade na redução da carga viral e sintomas clínicos. } \\
\text { Efeitos adversos não significativos. }\end{array}$ \\
\hline & Remdesivir & Wang et al. (2020) & $\begin{array}{l}\text { Ensaio } \\
\text { clínico/Rela } \\
\text { to de caso }\end{array}$ & $\begin{array}{l}\text { Efetividade na redução do tempo de recuperação dos pacientes e } \\
\text { do tempo de hospitalização. Sem efeitos clínicos ou antivirais } \\
\text { significativos em pacientes graves. Ineficaz em relação a redução } \\
\text { da taxa de mortalidade. Lesão renal aguda e erupção cutânea, } \\
\text { com hepatite citolítica foram observadas em alguns pacientes. }\end{array}$ \\
\hline & Favipiravir & Murai et al. (2020) & $\begin{array}{l}\text { Relato de } \\
\text { caso/Ensaio } \\
\text { clínico }\end{array}$ & $\begin{array}{l}\text { Efetividade na redução da carga viral nos casos leves à } \\
\text { moderados da doença. Pode reduzir o período de hospitalização e } \\
\text { a necessidade de ventilação mecânica. Porém requer atenção } \\
\text { quanto a segurança por suas características hepatotóxicas. }\end{array}$ \\
\hline & Umifenovir & Nomoji et al. (2020) & $\begin{array}{l}\text { Ensaio } \\
\text { clínico }\end{array}$ & $\begin{array}{l}\text { Efetividade significativa em relação às condições clínicas e } \\
\text { laboratoriais, incluindo redução do tempo de hospitalização em } \\
\text { UTI. Eventos adversos graves não foram relatados. }\end{array}$ \\
\hline & $\begin{array}{l}\text { Sofosbuvir / } \\
\text { Ledipasvir }\end{array}$ & Khalili et al. (2020) & $\begin{array}{l}\text { Ensaio } \\
\text { clínico }\end{array}$ & $\begin{array}{l}\text { Nos casos leves a moderados de COVID-19, não foi observado a } \\
\text { eficácia em relação a taxa de resposta clínica, tempo da } \\
\text { hospitalização e taxa de mortalidade. Nenhum evento adverso } \\
\text { significativo foi relatado. }\end{array}$ \\
\hline & $\begin{array}{l}\text { Lopinavir / } \\
\text { Ritonavir }\end{array}$ & $\begin{array}{l}\text { Cao et al. }(2020) \\
\text { Horby et al. }(2020) \\
\text { Lu et al. }(2020)\end{array}$ & $\begin{array}{l}\text { Ensaio } \\
\text { clínico }\end{array}$ & $\begin{array}{l}\text { Nenhum benefício foi observado em adultos hospitalizados com } \\
\text { COVID-19 grave. }\end{array}$ \\
\hline & $\begin{array}{l}\text { Lopinavir / } \\
\text { Ritonavir + } \\
\text { Umifenovir }\end{array}$ & Lan et al. (2020) & $\begin{array}{l}\text { Estudo de } \\
\text { caso }\end{array}$ & $\begin{array}{l}\text { Nenhum benefício foi observado no efeito antiviral de lopinavir- } \\
\text { ritonavir combinado com Umifenovir em comparação com } \\
\text { lopinavir-ritonavir sozinho em pacientes hospitalizados com } \\
\text { COVID-19. }\end{array}$ \\
\hline $\begin{array}{l}\text { Antivirais de ação } \\
\text { direta_(J05A) } \pm \\
\text { Imunoestimulante } \\
\quad(\mathrm{L} 03 \mathrm{~A})\end{array}$ & $\begin{array}{l}\text { Lopinavir / } \\
\text { Ritonavir }+ \\
\text { Ribavirina }+ \\
\text { Interferon } \beta 1-b\end{array}$ & $\begin{array}{l}\text { Hung et al. } \\
\qquad(2020)\end{array}$ & $\begin{array}{l}\text { Ensaio } \\
\text { clínico }\end{array}$ & $\begin{array}{l}\text { Efetividade na redução da carga viral, duração do tempo de } \\
\text { hospitalização e melhora clínica dos pacientes. Os efeitos } \\
\text { colaterais apresentados foram leves e autolimitados. }\end{array}$ \\
\hline $\begin{array}{l}\text { Antivirais de ação } \\
\text { direta }(\mathrm{J} 05 \mathrm{~A})+ \\
\text { Imunoestimulante } \\
\quad \text { (L03A) }\end{array}$ & $\begin{array}{l}\text { Favipiravir }+ \\
\text { Interferon } \beta 1-b\end{array}$ & Khamis et al. (2020) & $\begin{array}{l}\text { Ensaio } \\
\text { clínico }\end{array}$ & $\begin{array}{l}\text { Os resultados deste estudo não apresentou diferenças nos } \\
\text { marcadores inflamatórios ou nos desfechos clínicos nos pacientes } \\
\text { com pneumonia moderada a grave tratados } \\
\text { com Favipiravir e Interferon } \beta \text {-1b inalado, em comparação com a } \\
\text { Hidroxicloroquina. }\end{array}$ \\
\hline \multirow[b]{2}{*}{$\begin{array}{l}\text { Antigotas } \\
\text { (M04A) }\end{array}$} & Colchicina & $\begin{array}{l}\text { Deftereos et } \\
\text { al.(2020); Lopes et } \\
\text { al. (2020) }\end{array}$ & $\begin{array}{l}\text { Ensaio } \\
\text { clínico }\end{array}$ & $\begin{array}{l}\text { Efetividade na recuperação clínica dos pacientes e redução do } \\
\text { tempo de hospitalização. }\end{array}$ \\
\hline & Febuxostate & $\begin{array}{l}\text { Davoodi et al. } \\
\qquad(2020)\end{array}$ & $\begin{array}{l}\text { Ensaio } \\
\text { clínico }\end{array}$ & $\begin{array}{l}\text { Em pacientes adultos com infecção moderada por COVID-19, } \\
\text { não apresentou efetividade significativa em relação a resolução } \\
\text { das manifestações clínicas, exames laboratoriais e achados de } \\
\text { tomografia computadorizada pulmonar. Porém, o fármaco pode } \\
\text { ser considerado em pacientes que não podem utilizar a HCQ por } \\
\text { apresentar doenças cardiovasculares subjacentes. }\end{array}$ \\
\hline \multirow[b]{2}{*}{$\begin{array}{l}\text { Glucocorticóides } \\
\text { (H02AB) }\end{array}$} & Dexametasona & $\begin{array}{l}\text { Tomazini et al. } \\
\qquad(2020)\end{array}$ & $\begin{array}{l}\text { Ensaio } \\
\text { clínico }\end{array}$ & Ineficaz, sendo que as taxas de mortalidade foram altas. \\
\hline & $\begin{array}{l}\text { Metilprednisolo } \\
\text { na }\end{array}$ & $\begin{array}{l}\text { Corral-Gudino et al. } \\
(2020) \text {; Jeronimo et } \\
\text { al. }(2021)\end{array}$ & $\begin{array}{l}\text { Ensaio } \\
\text { clínico }\end{array}$ & $\begin{array}{l}\text { Efetividade significativa no desfecho clínico da pneumonia } \\
\text { grave, reduzindo o tempo de hospitalização em UTI e risco de } \\
\text { morte. }\end{array}$ \\
\hline
\end{tabular}


Classes

Farmacológicas

(Segundo ATC,

2021)

Fármacos

Referências

Tipo de

Desfecho

(Código)

\begin{tabular}{|c|c|c|c|c|}
\hline \multirow{2}{*}{$\begin{array}{l}\text { Antibacterianos para } \\
\text { uso sistêmico } \\
\text { (J01A) }\end{array}$} & Doxiciclina & $\begin{array}{l}\text { Butler et al. } \\
\quad(2020)\end{array}$ & $\begin{array}{l}\text { Ensaio } \\
\text { clínico }\end{array}$ & $\begin{array}{l}\text { Ineficaz e pode provocar o aumento da resistência } \\
\text { antimicrobiana. }\end{array}$ \\
\hline & Azitromicina & $\begin{array}{l}\text { Hinks et al. (2020); } \\
\text { Sekhavati et } \\
\text { al.(2020) }\end{array}$ & $\begin{array}{l}\text { Ensaio } \\
\text { clínico }\end{array}$ & $\begin{array}{l}\text { Nos pacientes com quadro leve a moderado da doença, não reduz } \\
\text { o risco, nem o tempo de hospitalização ou taxa de mortalidade. }\end{array}$ \\
\hline
\end{tabular}

Corticosteroides (H02A)

Hidrocortisona

Angus et al. (2020);

Ensaio

Baixa efetividade na redução da taxa de mortalidade e

clínico necessidade de ventilação mecânica invasiva.

$\begin{array}{llll}\text { Antirreumático } & \text { Baracitinibe } * & \begin{array}{l}\text { Bronte et al.(2020). } \\ \text { Hasan et al. (2020) }\end{array} & \begin{array}{l}\text { Ensaio } \\ \text { clínico }\end{array}\end{array}$

Quando administrado a dose usual (4 mg, 2 vezes ao dia durante 2 dias, seguido de $4 \mathrm{mg}$ ao dia por 7 dias), apresentou efetividade potencial no tratamento, reduzindo a progressão da doença para a forma grave e extrema, resultando em um desfecho clínico mais seguro e favorável aos pacientes com pneumonia por SARSCoV-2. Eventos adversos, como trombocitose e inflamações bucais foram observados em menos de $4 \%$ dos pacientes. No entanto, outro estudo demonstrou que a dose oral diária de $8 \mathrm{mg}$ por 14 dias revelou normalização precoce da função respiratória, redução da necessidade de hospitalização em UTI e do suporte de oxigênio, redução da taxa de mortalidade e taxa de reinternação em comparação com os $4 \mathrm{mg}$ usuais. Porém, os mesmos eventos adversos observados na terapêutica com a dose usual do fármaco, foram observados em $13 \%$ dos pacientes em que foram administrados $8 \mathrm{mg}$.

\begin{tabular}{|c|c|c|c|c|}
\hline $\begin{array}{l}\text { Antirreumático + } \\
\text { Antiviral de ação } \\
\quad \text { direta }\end{array}$ & $\begin{array}{l}\text { Baracitinibe } *+ \\
\text { Remdesivir }\end{array}$ & Kalil et al. (2020) & $\begin{array}{l}\text { Ensaio } \\
\text { clínico }\end{array}$ & $\begin{array}{l}\text { Efetividade na melhora do estado clínico dos pacientes, } \\
\text { principalmente entre aqueles que receberam oxigênio de alto } \\
\text { fluxo ou ventilação mecânica não invasiva. A associação dos } \\
\text { fármacos foi relacionada à redução de eventos adversos graves. }\end{array}$ \\
\hline \multirow[t]{2}{*}{$\begin{array}{l}\text { Antimaláricos } \\
\text { (P01B) }\end{array}$} & $\begin{array}{l}\text { Hidroxicloroqui } \\
\text { na / Cloroquina }\end{array}$ & $\begin{array}{l}\text { Chen et al.(2020); } \\
\text { Gautret et al. } \\
(2020) \text {; Mitjà et } \\
\text { al.(2020); Tang et } \\
\text { al.(2020); }\end{array}$ & $\begin{array}{l}\text { Ensaio } \\
\text { clínico }\end{array}$ & $\begin{array}{l}\text { Ineficaz e com potenciais deletérios ao sistema cardiovascular. } \\
\text { Os eventos adversos observados são triplicados em comparação } \\
\text { ao placebo. Está associado ao aumento do tempo de internação } \\
\text { hospitalar e aumento do risco de progressão à ventilação } \\
\text { mecânica até morte. }\end{array}$ \\
\hline & $\begin{array}{l}\text { Artemisinina- } \\
\text { Piperaquina }\end{array}$ & $\begin{array}{l}\text { Li et al. } \\
(2020)\end{array}$ & $\begin{array}{l}\text { Ensaio } \\
\text { clínico }\end{array}$ & $\begin{array}{l}\text { Efetividade na redução do tempo de permanência do vírus no } \\
\text { organismo dos pacientes e melhora da função pulmonar. }\end{array}$ \\
\hline $\begin{array}{l}\text { Agente } \\
\text { antinematódico } \\
\text { (P02C) }\end{array}$ & Ivermectina & $\begin{array}{l}\text { Hosseini et } \\
\text { al.(2020); Rajter et } \\
\text { al. (2020) }\end{array}$ & $\begin{array}{l}\text { Ensaio } \\
\text { clínico }\end{array}$ & $\begin{array}{l}\text { Efetividade na recuperação clínica, melhora dos parâmetros } \\
\text { laboratoriais e redução da taxa de mortalidade, especialmente em } \\
\text { pacientes com envolvimento pulmonar grave. }\end{array}$ \\
\hline $\begin{array}{c}\text { Agente } \\
\text { antinematódico } \\
(\mathrm{P} 02 \mathrm{C}) \\
+ \\
\text { Tetraciclina (J01A) }\end{array}$ & $\begin{array}{c}\text { Ivermectina }+ \\
\text { Doxiciclina }\end{array}$ & $\begin{array}{l}\text { Mahmud et al. } \\
\qquad(2020)\end{array}$ & $\begin{array}{l}\text { Ensaio } \\
\text { clínico }\end{array}$ & $\begin{array}{l}\text { Efetividade na recuperação clínica, redução do tempo de } \\
\text { hospitalização e da taxa de mortalidade. }\end{array}$ \\
\hline $\begin{array}{l}\text { Agentes contra } \\
\text { amebíase e outras } \\
\text { doenças protozoárias } \\
\text { (P01A) }\end{array}$ & Nitazoxanida & $\begin{array}{l}\text { Meneses et al. } \\
\quad(2020)\end{array}$ & $\begin{array}{l}\text { Estudo de } \\
\quad \text { caso }\end{array}$ & $\begin{array}{l}\text { Efetividade na recuperação clínica do paciente, não apenas em } \\
\text { uma intervenção precoce, mas também em condições graves, } \\
\text { inclusive na gravidez, sem efeitos indesejáveis para os bebês. }\end{array}$ \\
\hline $\begin{array}{l}\text { Bloqueadores do } \\
\text { receptor de } \\
\text { angiotensina II } \\
(\mathrm{C} 09 \mathrm{C})\end{array}$ & Losartan & $\begin{array}{l}\text { Bengston et al. } \\
\qquad(2020)\end{array}$ & $\begin{array}{l}\text { Ensaio } \\
\text { clínico }\end{array}$ & Efetividade na redução da lesão pulmonar provocada pelo vírus. \\
\hline
\end{tabular}




\begin{tabular}{|c|c|c|c|c|}
\hline $\begin{array}{c}\text { Classes } \\
\text { Farmacológicas } \\
\text { (Segundo ATC, } \\
\text { 2021) } \\
\text { (Código) }\end{array}$ & Fármacos & Referências & $\begin{array}{l}\text { Tipo de } \\
\text { Estudo }\end{array}$ & Desfecho \\
\hline$\frac{\text { Agentes antitrombóti }}{\underline{\underline{\cos }}}$ & $\begin{array}{c}\text { Heparina } \\
\text { Enoxaparina }\end{array}$ & $\begin{array}{l}\text { Di Castelnuovo et al } \\
\qquad(2020) ; \\
\text { Lemos et al. (2020) }\end{array}$ & $\begin{array}{l}\text { Ensaio } \\
\text { clínico }\end{array}$ & $\begin{array}{l}\text { Efetividade na redução significativa da taxa de mortalidade } \\
\text { particularmente entre os pacientes graves. }\end{array}$ \\
\hline $\begin{array}{l}\text { Antidepressivo } \\
\text { (N06A) }\end{array}$ & Fluvoxamina & $\begin{array}{l}\text { Lenze et al. } \\
\quad(2020)\end{array}$ & $\begin{array}{l}\text { Ensaio } \\
\text { clínico }\end{array}$ & $\begin{array}{l}\text { Provável eficácia na prevenção da deterioração clínica ao } \\
\text { estimular o receptor } \sigma-1 \text {, que regula a produção de citocinas. } \\
\text { Algumas vantagens potenciais para o tratamento ambulatorial da } \\
\text { COVID-19 incluem segurança, ampla disponibilidade, baixo } \\
\text { custo e administração oral. No entanto, apresenta efeitos } \\
\text { adversos (pneumonia e sintomas gastrointestinais, como náuseas } \\
\text { e vômitos) e também pode provocar interações medicamentosas, } \\
\text { principalmente por meio da inibição dos citocromos P450 1A2 e } \\
\text { 2C19. }\end{array}$ \\
\hline
\end{tabular}

\begin{tabular}{ccccc}
\hline $\begin{array}{c}\text { Vasodilatador } \\
\text { periférico } \\
\text { (C04A) }\end{array}$ & Pentoxifilina & $\begin{array}{c}\text { Maldonado et al. } \\
(2020)\end{array}$ & $\begin{array}{c}\text { Estudo de } \\
\text { caso }\end{array}$ & $\begin{array}{c}\text { Ineficaz. Não reduz o tempo de internação nem a taxa de } \\
\text { mortalidade. }\end{array}$ \\
$\begin{array}{c}\text { Expectorante / } \\
\text { Mucolítico } \\
\text { (R05C) }\end{array}$ & $\begin{array}{c}\text { Cloridrato de } \\
\text { Bromexina }\end{array}$ & $\begin{array}{c}\text { Ansarin et al. } \\
(2020) ; \text { Li et } \\
\text { al.(2020) }\end{array}$ & $\begin{array}{c}\text { Estudo de } \\
\text { caso/Ensaio } \\
\text { clínico }\end{array}$ & $\begin{array}{c}\text { Efetividade em pacientes com lesão pulmonar ou hepática. } \\
\text { hospitalização em UTI, ventilação mecânica e taxa de } \\
\text { mortalidade. }\end{array}$ \\
\hline
\end{tabular}

Imunoestimulante

(L03A)
Interferon $\beta-1 \mathrm{a}$

Davoudi- Monfared

et al. (2020)
Embora não tenha alterado o tempo para atingir uma resposta clínica, aumentou significativamente a taxa de alta hospitalar e reduziu a taxa de mortalidade. A taxa de sobrevida melhorada foi significativa quando os pacientes receberam IFN $\beta$-1a na fase inicial da doença. Os efeitos adversos relatados foram: problemas neuropsiquiátricos e reações de hipersensibilidade.

\section{Meplazumabe* Bia et al. Ensaio Efetividade significativa na redução do tempo de hospitalização (2020) clínico na progressão da gravidade dos sintomas clínicos.}

$\begin{array}{ccc}\begin{array}{c}\text { Bamlanivimabe } \\ *\end{array} & \begin{array}{c}\text { Chen et al.(2020); } \\ \text { Cohen et al. (2020) }\end{array} & \text { Ensaínico } \\ & \text { clico }\end{array}$

Imunomoduladores

$\begin{array}{cc}\text { Baum et al. (2020); } & \text { Weinreich et } \\ \text { al.(2020) }\end{array}$

Estudo

clínico
Efetividade na redução da carga viral e da exposição antigênica. Os eventos adversos relatados foram infecção gastrointestinal e hipertensão.

Efetividade na redução da carga viral, com maior efeito em pacientes cuja resposta imune ainda não havia sido iniciada (ou seja, anticorpos séricos negativos) ou que apresentavam carga viral elevada no início do estudo e melhora potencial nos desfechos clínicos. Apresenta baixa incidência de eventos adversos graves ou agravados durante o período de observação e de reações relacionadas com a perfusão ou de hipersensibilidade.

Efetividade na redução da carga viral. Reações de hipersensibilidade imediata foram os eventos adversos relatados pelos pacientes.
Bamlanivimabe

+ Etesevimabe*

\section{Gottlieb et al.} (2020)
Ensaio

clínico 


\begin{tabular}{|c|c|c|c|c|}
\hline $\begin{array}{c}\text { Classes } \\
\text { Farmacológicas } \\
\text { (Segundo ATC, } \\
\text { 2021) } \\
\text { (Código) } \\
\end{array}$ & Fármacos & Referências & $\begin{array}{l}\text { Tipo de } \\
\text { Estudo }\end{array}$ & Desfecho \\
\hline \multirow{2}{*}{$\begin{array}{l}\text { Imunomoduladores } \\
\text { (L04A) }\end{array}$} & Tocilizumabe & $\begin{array}{l}\text { Rajendram et al. } \\
\text { (2020); } \\
\text { Salama et al.(2020); } \\
\text { Salvarani et } \\
\text { al.(2020); } \\
\text { Strohbehn et } \\
\text { al.(2020) }\end{array}$ & $\begin{array}{l}\text { Ensaio } \\
\text { clínico }\end{array}$ & $\begin{array}{l}\text { Nos pacientes hospitalizados com pneumonia grave por SARS- } \\
\text { CoV-2, demonstrou potencial efetividade na redução da taxa de } \\
\text { mortalidade de pacientes com insuficiência respiratória } \\
\text { hipoxêmica grave, da taxa de mortalidade, da probabilidade de } \\
\text { progressão para o desfecho composto de ventilação mecânica ou } \\
\text { morte e melhora dos desfechos clínicos. Já nos pacientes com } \\
\text { pneumonia moderada, não reduziu o risco de piora clínica. }\end{array}$ \\
\hline & Anakinra & $\begin{array}{l}\text { Xavier et al. } \\
\text { (2020) }\end{array}$ & $\begin{array}{l}\text { Ensaio } \\
\text { clínico }\end{array}$ & $\begin{array}{l}\text { Efetividade na redução da necessidade de ventilação não invasiva } \\
\text { ou mecânica, da taxa de mortalidade em pacientes com } \\
\text { pneumonia leve à moderada, da carga viral e do tempo de } \\
\text { hospitalização. }\end{array}$ \\
\hline
\end{tabular}

\begin{tabular}{|c|c|c|c|c|}
\hline $\begin{array}{c}\text { Agente } \\
\text { antineoplásico } \\
\text { (inibidores de } \\
\text { proteína quinase) } \\
\text { (L01E) } \\
\end{array}$ & Ruxolitinibe & $\begin{array}{l}\text { Cao et al. } \\
(2020)\end{array}$ & $\begin{array}{l}\text { Ensaio } \\
\text { clínico }\end{array}$ & $\begin{array}{l}\text { Efetividade significativa na melhora clínica e na recuperação da } \\
\text { linfopenia. A anemia foi o evento adverso relatado pelos } \\
\text { pacientes. }\end{array}$ \\
\hline $\begin{array}{l}\text { Imunomodulador } \\
\text { (L04A) + Esteroides }\end{array}$ & $\begin{array}{l}\text { Tocilizumabe + } \\
\text { Esteroides }\end{array}$ & $\begin{array}{l}\text { Ruiz et al. } \\
\text { (2020) }\end{array}$ & $\begin{array}{l}\text { Estudo } \\
\text { multicêntric } \\
\quad \text { o }\end{array}$ & $\begin{array}{l}\text { Efetividade na redução da taxa de mortalidade, principalmente } \\
\text { quando administrado nas primeiras } 48 \text { horas após a manifestação } \\
\text { da insuficiência respiratória. Aumento da sobrevida em pacientes } \\
\text { graves. }\end{array}$ \\
\hline $\begin{array}{l}\text { Imunomodulador } \\
\text { (L04A) + Antivirais } \\
\text { de ação direta } \\
\text { (J05A) }\end{array}$ & $\begin{array}{l}\text { Tocilizumabe }+ \\
\text { Favipiravir }\end{array}$ & $\begin{array}{l}\text { Zhao et al. } \\
\text { (2020) }\end{array}$ & $\begin{array}{l}\text { Ensaio } \\
\text { clínico }\end{array}$ & $\begin{array}{l}\text { Efetividade na redução da inflamação pulmonar e da taxa de } \\
\text { mortalidade. Efetividade na melhora dos sintomas clínicos. Não } \\
\text { houve relatos de reações adversas graves. }\end{array}$ \\
\hline $\begin{array}{c}\text { Imunoestimulante } \\
(\text { L03A) + } \\
\text { Antimalárico (P01B) } \\
\text { + Antivirais de ação } \\
\text { direta } \\
(\mathrm{J} 05 \mathrm{~A}) \\
\end{array}$ & $\begin{array}{c}\text { Interferon } \beta-1 \mathrm{~b} \\
+ \\
\text { Hidroxicloroqui } \\
\text { na }+ \\
\text { Lopinavir/Riton } \\
\text { avir } \\
\end{array}$ & $\begin{array}{l}\text { Dastan et al. } \\
\quad(2020)\end{array}$ & $\begin{array}{l}\text { Ensaio } \\
\text { clínico }\end{array}$ & Efetividade na redução dos sintomas clínicos. \\
\hline $\begin{array}{c}\text { Imunoestimulante } \\
\text { (L03A) }+ \\
\text { Antivirais de ação } \\
\text { direta } \\
\text { (J05A) } \\
\end{array}$ & $\begin{array}{c}\text { Interferon } \beta \text {-1b } \\
+ \\
\text { Lopinavir/Riton } \\
\text { avir }+ \\
\text { Ribavirina } \\
\end{array}$ & $\begin{array}{l}\text { Hung et al. } \\
\text { (2020) }\end{array}$ & $\begin{array}{l}\text { Estudo } \\
\text { multicêntric } \\
\text { o }\end{array}$ & $\begin{array}{l}\text { Efetividade na redução dos sintomas clínicos, da carga viral e } \\
\text { também do tempo de hospitalização em pacientes com casos } \\
\text { leves à moderados da doença. }\end{array}$ \\
\hline $\begin{array}{l}\text { Imunoglobulina } \\
\text { (Monoterapia) } \\
\quad \text { (J06B) }\end{array}$ & $\begin{array}{l}\text { Imunoglobulina } \\
\text { Gama }\end{array}$ & $\begin{array}{c}\text { Gharebaghi et al. } \\
(2020)\end{array}$ & $\begin{array}{l}\text { Ensaio } \\
\text { clínico }\end{array}$ & $\begin{array}{l}\text { Efetividade em pacientes com infecção grave, melhorando o } \\
\text { resultado clínico e reduzindo significativamente a taxa de } \\
\text { mortalidade. }\end{array}$ \\
\hline $\begin{array}{c}\text { Imunoglobulina } \\
(\mathrm{J} 06 \mathrm{~B})+ \\
\text { Antimalárico (P01B) } \\
+ \text { Antivirais de ação } \\
\text { direta (J05A) }\end{array}$ & $\begin{array}{c}\text { Imunoglobulina } \\
\text { Gama }+ \\
\text { Hidroxicloroqui } \\
\text { na }+ \\
\text { Lopinavir/Riton } \\
\text { avir } \\
\end{array}$ & $\begin{array}{l}\text { Tabarsi et al. } \\
\text { (2020) }\end{array}$ & $\begin{array}{l}\text { Ensaio } \\
\text { clínico }\end{array}$ & A associação de IVIg não apresentou eficácia terapêutica. \\
\hline $\begin{array}{l}\text { Vitamina }(\mathrm{A} 11 \mathrm{G})+ \\
\text { Antivirais de ação } \\
\text { direta }(\mathrm{J} 05 \mathrm{~A})+ \\
\text { Antimalárico }(\mathrm{P} 01 \mathrm{~B})\end{array}$ & $\begin{array}{c}\text { Ácido } \\
\text { Ascórbico + } \\
\text { Lopinavir/Riton } \\
\text { avir }+ \\
\text { Hidroxicloroqui } \\
\text { na } \\
\end{array}$ & $\begin{array}{l}\text { Jamali et al.(2020); } \\
\text { Thomas et al. } \\
\text { (2020) }\end{array}$ & $\begin{array}{l}\text { Ensaio } \\
\text { clínico }\end{array}$ & $\begin{array}{l}\text { Quando administrado via intravenosa em altas doses, como } \\
\text { adjuvante no tratamento da COVID-19, não apresentou eficácia } \\
\text { terapêutica. Não houve relatos de eventos adversos graves. }\end{array}$ \\
\hline $\begin{array}{c}\text { Plasma convalescente } \\
\text { (B05A) }\end{array}$ & $\begin{array}{c}\text { Plasma } \\
\text { Convalescente }\end{array}$ & $\begin{array}{c}\text { Agarwal et } \\
\text { al.(2020); Li et al. } \\
\text { (2020); Horby et } \\
\text { al.(2020); Kurtz et } \\
\text { al. (2020); } \\
\text { Libster et al.(2020); }\end{array}$ & $\begin{array}{l}\text { Ensaio } \\
\text { clínico }\end{array}$ & $\begin{array}{l}\text { Embora estudos observacionais tenham demonstrado } \\
\text { consistentemente que o plasma convalescente possui perfil de } \\
\text { segurança adequado, seu uso em pacientes graves não apresentou } \\
\text { efetividade em relação a melhora clínica e não reduziu a taxa de } \\
\text { mortalidade. Nos casos leves a moderados, não foi associado a } \\
\text { uma redução na progressão para a forma grave. Porém, a }\end{array}$ \\
\hline
\end{tabular}


Salazar et al.(2020);

Schwartz et

al.(2020);

Simonovich et al.(2020) administração precoce, em idosos, reduziu a progressão da doença. Os eventos adversos relatados foram erupções cutâneas, reação transfusional alérgica não severa definitiva, reação transfusional febril não hemolítica não severa, falta de ar, cianose e dispneia grave.

Fonte: Furuzawa et al. (2021).

\subsection{Antivirais de ação direta (monoterapia)}

Os antivirais são subdivididos em análogos de nucleosídeo e inibidores de neuraminidases. Os análogos de nucleosídeo interrompem a replicação viral em sua fase inicial, através do bloqueio da enzima RNA polimerase e consequentemente, inibem a síntese de RNA viral. Já os inibidores de neuraminidases atuam através do bloqueio desta enzima, que é fundamental para a síntese de RNA viral. Desta forma, seu bloqueio impede a replicação do vírus e a evolução da COVID-19 (Barlow et al., 2020).

O Remdesivir é um pró-fármaco de um análogo da adenosina, que é metabolizado em um nucleosídeo trifosfato ativo pelo hospedeiro. Como análogo de nucleosídeo, atua como um inibidor de RNA polimerase dependente de RNA (RdRp), visando interromper o processo de replicação do genoma viral. O RdRp é o complexo proteico usado pelos Coronavirus para replicar seus genomas baseados em RNA (Amirian \& Levy, 2020). O fármaco foi o primeiro antiviral a ter indicação aprovada, em bula, contra o SARS-CoV-2, no Brasil. Nos EUA, foi aprovado pelo FDA para uso emergencial no tratamento da COVID19 em outubro de 2020 e pela ANVISA em março de 2021 para uso exclusivo no tratamento de pacientes hospitalizados com quadro de pneumonia e que necessitam de suporte de oxigênio, desde que não estejam em ventilação mecânica.

Em pacientes graves, o Remdesivir não obteve efeitos clínicos significativos. Também não resultou em reduções significativas das cargas de RNA do vírus SARS-CoV-2, não reduziu o tempo de melhora clínica, nem a taxa de mortalidade ou o tempo de depuração do vírus. Deve ser realizado um monitoramento rigoroso dos testes hepáticos e renais dos pacientes, pois o fármaco pode provocar eventos adversos graves, como lesão renal aguda e erupção maculopapular com hepatite citolítica (Dubert et al., 2020; Goldman, et al, 2020; Pasquini et al., 2020; Wang et al., 2020).

Alguns fármacos, como o Molnupiravir, não constam na classificação ATC 2021, porém são classificados como antivirais de amplo espectro. O fármaco antiviral experimental produzido pela Indústria Farmacêutica Merck, o Molnupiravir, é um pró-fármaco do derivado nucleosídeo sintético N4-hidroxicitidina, que exerce sua ação antiviral por meio da introdução de erros de cópia durante a replicação do RNA viral. Em ensaio clínico, foi eficaz na redução da carga viral e dos danos pulmonares, porém não deve ser administrado em gestantes ou mulheres em idade reprodutiva, devido ao seu potencial mutagênico. No entanto, é uma opção de tratamento via oral fácil de sintetizar, que reduz a duração da infecciosidade entre as pessoas com COVID-19 sintomático (Abdelnabi et al., 2021).

O Oseltamivir, conhecido e comercializado como Tamiflu ${ }^{\circledR}$ (Roche), é um pró- fármaco inibidor potente e seletivo de neuraminidase amplamente prescrito para o tratamento da influenza em todo o mundo após o surto de influenza A (H1N1) em 2009. No estudo, não apresentou efetividade no tratamento específico da COVID-19, porém, a administração precoce associada com terapia antibacteriana, pode reduzir os sintomas, como febre, fadiga, dor de garganta e tosse (Chiba, 2020).

Aprovado no Japão em 2014 para tratamento de infecções por influenza, Avigan® (Fujifilm Holdings Corp), como é comercializado o antiviral Favipiravir, foi aprovado em 2020 por alguns países, como Rússia e Índia para o tratamento da COVID-19. É um análogo de nucleosídeo, que inibe a síntese de RNA do vírus (Shiraki, 2020). Este fármaco apresentou efetividade na redução da carga viral nos casos leves à moderados da doença, podendo reduzir o período de hospitalização e a necessidade de ventilação mecânica. Porém, o monitoramento da função hepática é vital e requer atenção por suas características hepatotóxicas (Dabbous et al., 2020; Irie et al., 2020; Murai et al., 2020; Yamazaki et al.,2020). 
Conhecido como Arbidol $^{\circledR}$ (OTC Pharm), o Umifenovir possui vários mecanismos de ação, pelos quais inibe etapas dos ciclos de vida do vírus, sendo considerado um antiviral de ação direta. O principal mecanismo é o bloqueio do estágio inicial da replicação do vírus e a inibição da fusão da membrana, por meio da interação do fármaco com o envelope lipídico viral e com resíduos-chave dentro de proteínas estruturais, inibindo a entrada do vírus nas células alvo (Blaising et al., 2014).

O Umifenovir apresentou efetividade na melhora clínica e dos parâmetros laboratoriais, inclusive saturação periférica de oxigênio e também na redução do tempo de hospitalização em UTI. Eventos adversos graves não foram relatados (Nomoji et al, 2020).

Os antivirais de ação direta Sofosbuvir / Ledipasvir, são análogos de nucleotídeos, sendo que o primeiro, é responsável pela inibição do NS5B-RdRp, que é uma enzima essencial no processo de replicação do vírus. No entanto, o Ledipasvir inibe o NS5A, necessário para a função RdRp. Portanto, eles agem sinergicamente. Em 2014, foram aprovados pelo FDA nos Estados Unidos, União Europeia e no Canadá, apenas para o tratamento de infecção provocada pelo vírus da hepatite C. Podem ser eficazes contra a COVID-19 porque o vírus SARS-CoV-2 e o vírus da hepatite C possuem proteínas e enzimas semelhantes necessárias para o processo de replicação (Elgohary et al, 2020).

Em estudo realizado por Khalili et al (2020), o uso de Sofosbuvir / Ledipasvir nos casos leves a moderados de COVID-19, não foi observado a eficácia em relação a taxa de resposta clínica, tempo da hospitalização e taxa de mortalidade. Nenhum evento adverso significativo foi relatado. Provavelmente, a terapêutica com os antivirais seria eficaz se fosse iniciada na fase antecedente a infecção, antes da ocorrência de danos significativos nos tecidos pulmonares. São fármacos disponíveis em vários países e podem desempenhar uma função importante no tratamento da COVID-19 leve a moderada. No entanto, são necessários ensaios clínicos com amostras maiores para confirmar a eficácia no tratamento da COVID-19.

$\mathrm{Na}$ seleção de agentes antivirais, foram estudados também os antirretrovirais Lopinavir e Ritonavir, utilizados no tratamento de infecções pelo vírus da imunodeficiência humana (HIV). Segundo a ATC, são antivirais para tratamento de infecções por HIV e pertencem a classe dos inibidores de protease. O Ritonavir inibe o citocromo P450 e com isso, aumentando a meia-vida plasmática do Lopinavir. A atividade antiviral desta associação farmacológica está relacionada com a inibição da enzima protease 3-quimiotripsina, encontrada no SARS-CoV-2, interrompendo o processo de replicação e liberação viral das células hospedeiras (Zhang et al, 2020).

Com base nos resultados obtidos no ensaio clínico de Lan et al. (2020), foi possível observar que nenhum benefício foi observado no efeito antiviral da associação Lopinavir-Ritonavir combinado com Umifenovir em comparação com Lopinavir-Ritonavir em monoterapia, em pacientes hospitalizados com COVID-19.

\subsection{Antivirais de ação direta + associações}

Em estudo clínico realizado por Khamis et al. (2020), com objetivo de avaliar a eficácia terapêutica da associação do Favipiravir com o Interferon beta-1b inalado ou Hidroxicloroquina, foram acompanhados pacientes adultos hospitalizados com pneumonia por COVID-19 moderada a grave. Os autores sugerem que a associação do antiviral com o imunoestimulante não apresenta eficácia significativamente diferente em comparação a HCQ no que diz respeito ao tempo total de hospitalização, transferências para UTI, saturação de oxigênio e taxa de mortalidade. No entanto, os resultados indicaram que o Interferon beta-1b é seguro e pode ser um tratamento eficaz contra a COVID-19 nos estágios iniciais da infecção, mas não em estágio avançados. A realização de ensaios clínicos deve comprovar a eficácia desta imunoterapia.

O Lopinavir associado a Interferons, particularmente o Interferon beta, possuem baixa atividade contra o SARS-CoV2, podendo ser utilizados de forma sinérgica com a Ribavirina (Chan et al., 2013).

Em 2020, um estudo multicêntrico prospectivo aberto avaliou a eficácia e segurança da associação de Interferon beta1b, Lopinavir-Ritonavir e Ribavirina para o tratamento de pacientes adultos com COVID-19 leve a moderada. Apesar das 
limitações do estudo, foi possível concluir que a terapia antiviral tripla quando administrada precocemente, foi segura e superior ao Lopinavir-Ritonavir em monoterapia na melhoria dos sintomas e na redução da duração da eliminação viral e do tempo de hospitalização. Apesar da preocupação em relação aos efeitos adversos decorrentes da associação de três fármacos, não ocorreu nenhuma diferença significativa na incidência dos mesmos (Hung et al., 2020).

\subsection{Antigotas}

Com poderosa ação anti-inflamatória, a Colchicina é amplamente utilizada no tratamento e profilaxia de crises agudas de gota e em outras patologias articulares. Os mecanismos de ação pelos quais o fármaco desempenha sua ação antiinflamatória são: inibição do inflamassoma de NLRP3; comprometimento da funcionalidade do citoesqueleto (prevenção da mitose, motilidade celular, adesão, quimiotaxia e internalização viral) e redução da resposta inflamatória, especialmente em granulócitos e monócitos. No entanto, o uso deste fármaco em pacientes com COVID-19 pode impedir a entrada do vírus e neutralizar o estado hiperinflamatório. Um estudo realizado por Deftereos et al. (2020) sugeriu que a Colchicina é segura para pacientes com COVID-19 e pode melhorar os resultados em relação a redução do tempo de oxigenoterapia suplementar e tempo de hospitalização. Porém, esses dados precisarão ser corroborados com estudos maiores com maior amostragem e de duração prolongada. A maior parte dos eventos adversos relatados foi leve, como diarreia e vômito.

O fármaco antigotoso estudado que pode apresentar efetividade contra o SARS-CoV-2, é o Febuxostate, um inibidor seletivo da xantina oxidase, a enzima que catalisa a síntese de ácido úrico a partir de hipoxantina e xantina. Alguns estudos demonstram que o fármaco pode inibir a resposta inflamatória por meio da redução dos níveis de mediadores próinflamatórios, como o fator de necrose tumoral (TNF)- $\alpha$, interleukin (IL)-1 $\beta$, IL-6 e NF-kB (Fahmi et al., 2016).

No ensaio clínico realizado por Davoodi et al. (2020), envolvendo pacientes adultos que apresentaram quadro moderado de infecção por COVID-19. Este fármaco não apresentou eficácia em relação a melhora das manifestações clínicas, exames laboratoriais e achados de tomografia computadorizada pulmonar em comparação com os pacientes que receberam apenas HCQ. Porém, pode ser um tratamento alternativo para os pacientes com contraindicação ou precaução a HCQ (Davoodi et al., 2020).

\subsection{Antibacterianos de uso sistêmico}

Os antibacterianos Azitromicina e Doxiciclina possuem atividade predominantemente bacteriostática, impedindo a multiplicação dos microrganismos de amplo espectro, sendo amplamente utilizados na atenção primária para o tratamento de infecções do trato respiratório (Butler et al., 2020; Sekhavati et al., 2020).

De acordo com o mecanismo de ação proposto, a Azitromicina pode reduzir a produção de citocinas pró-inflamatórias - como IL-8, IL-6, TNF alfa e metaloproteinases (MMPs) - e, no estágio de resolução, induz neutrófilos à apoptose e aumenta o estresse oxidativo relacionado à inflamação (Pani et al., 2020).

No estudo randomizado prospectivo conduzido por Hinks et al. (2020), os pacientes portadores de pneumonia grave, a administração de Azitromicina não demonstrou eficácia clínica em relação a redução da taxa de mortalidade, necessidade de ventilação mecânica invasiva e do tempo de hospitalização. Além disso, foram relatados alguns eventos adversos gastrointestinais, neurológicos, erupções cutâneas e perda auditiva. E alguns eventos adversos ainda mais severos também foram relatados, como eritema multiforme, miastenia gravis, trombocitopenia e quadro ictérico.

No entanto, um estudo conduzido por Sekhavati et al. (2020), relatou a eficácia da Azitromicina em relação ao período de hospitalização. Porém, um sistema de pontuação de risco deve ser utilizado antes de iniciar o tratamento para prevenir o prolongamento do QTc (prolongamento anormal de uma medida do eletrocardiograma, que ocorre por uma 
anormalidade nos canais de potássio ou sódio do coração e podem causar arritmias graves em indivíduos jovens e saudáveis), especialmente para pacientes de alto risco.

A Doxiciclina apresenta potencial mecanismo de ação que pode amenizar os efeitos da infecção provocada pelo SARS-CoV-2, sendo responsável por reduzir a produção de óxido nitroso e inibir a metaloproteinase-9 da matriz, que atua na síndrome do desconforto respiratório agudo. Administrado em baixas doses, o fármaco inibiu a expressão de que seria necessária à entrada do SARS-CoV-2 em Linfócitos T. Porém, o aumento do uso deste antibacteriano durante a pandemia de COVID-19 pode exacerbar a resistência antimicrobiana (Yates et al., 2020).

O ensaio clínico realizado no Reino Unido, em 2020, não recomendou o uso rotineiro da Doxiciclina em casos suspeitos de COVID-19, pois o uso mais amplo do fármaco pode provocar o aumento da resistência antimicrobiana. Além disto, Butler et al (2020) ressaltaram que seu uso não estava associado a reduções clinicamente significativas em relação ao tempo de recuperação, tempo de hospitalização ou taxa de mortalidade.

\subsection{Glucocorticóides}

O uso de Dexametasona no tratamento da COVID-19 é questionável, pois está relacionado com maior taxa de mortalidade e além de inibir citocinas inflamatórias, pode limitar a função protetora das células $\mathrm{T}$ e impedir a produção de anticorpos de células B, podendo resultar em maior carga viral plasmática e o aumento dos riscos de desenvolver infecções secundárias (Tomazini et al., 2020).

Em contrapartida, o uso de Metilprednisolona pode ser recomendado para pacientes com progressão rápida da doença, ou na presença da forma grave da doença, apresentando efetividade significativa no desfecho clínico da pneumonia grave, reduzindo o tempo de hospitalização em UTI e risco de morte (Corral- Gudino et al., 2020). Porém, outra preocupação com esses fármacos é o possível atraso na eliminação do vírus e as chances de estar relacionado com o aumento do risco do aparecimento de infecções secundárias, principalmente nos pacientes com comprometimento do sistema imunológico (Jeronimo et al., 2020).

\subsection{Corticosteroides}

O uso de corticosteroides foi associado à redução dos níveis de citocinas pró-inflamatórias e, devido a sua capacidade de reduzir a proliferação celular, estão sendo utilizados como adjuvantes no tratamento de formas graves da COVID-19 (Zhang et al., 2020).

A Hidrocortisona é um esteroide anti-inflamatório e imunossupressor que se difunde para o citoplasma celular, ligando- se ao seu receptor específico, permitindo a dimerização dos receptores e sua translocação para o núcleo da célula, interação com o DNA e modificação do processo de transcrição de genes específicos, modulando a expressão dos genes-alvo. Em um ensaio clínico randomizado francês, envolvendo 149 pacientes internados na unidade de terapia intensiva com insuficiência respiratória aguda relacionada a COVID-19 que receberam a terapêutica de Hidrocortisona em baixa dosagem, não houve redução significativa do número de óbitos (Dequin et al., 2020).

Em um ensaio clínico randomizado conduzido por Angus et al. (2020), embora a Hidrocortisona tenha apresentado benefícios significativos aos pacientes portadores da COVID-19 grave, o estudo foi interrompido precocemente e nenhuma estratégia de tratamento atendeu aos critérios pré-especificados de superioridade estatística, impedindo conclusões definitivas.

\subsection{Antirreumático e associação}

O Baracitinibe é um inibidor seletivo e reversível das enzimas janus quinases (JAKs), em especial JAK 1 e 2, responsáveis pela comunicação das células envolvidas na hematopoese (processo de formação e desenvolvimento das células 
do sangue), na inflamação e na função imunológica (Bronte et al., 2020). Este fármaco possui registro no Brasil para o tratamento de artrite reumatoide ativa moderada a grave e dermatite atópica moderada a grave e foi aprovada pela ANVISA, para o tratamento de pacientes adultos hospitalizados com COVID-19 que necessitam de oxigênio por máscara ou cateter nasal, ou que necessitam de alto fluxo de oxigênio ou ventilação não invasiva.

Uma dose oral diária de $8 \mathrm{mg}$ (alta dose) de Baracitinibe, por 14 dias revelou normalização precoce da função respiratória, redução da necessidade de hospitalização em UTI e suporte de intubação, redução da taxa de mortalidade em 30 dias e taxa de reinternação de 60 dias minimizada em comparação com os $4 \mathrm{mg}$ usuais dose oral diária no tratamento da pneumonia grave provocada pelo SARS-CoV-2. Porém, eventos adversos, tais como trombocitose e inflamações bucais foram observados em menos de $4 \%$ dos pacientes que receberam a dose usual do fármaco e em mais de $13 \%$ dos pacientes que receberam altas doses (Bronte et al., 2020; Hasan et al., 2020).

O Baracitinibe ainda não possui código de classificação ATC, porém consta na lista para a revisão de 3 anos pela WHO Collaborating Centre for Drug Statistics Methodology (WHO, 2021b).

Em um ensaio clínico conduzido por Kalil et al. (2020), a terapêutica com a associação do antirreumático Baricitinibe com o antiviral Remdesivir foi superior na eficácia da aceleração da melhora do estado clínico dos pacientes, principalmente entre aqueles que receberam oxigênio de alto fluxo ou ventilação não invasiva, comparando-se com a monoterapia do Remdesivir. A combinação dos fármacos foi associada a uma menor probabilidade de relatos de eventos adversos graves.

\subsection{Antimaláricos}

A Hidroxicloroquina (HCQ) e a Cloroquina (CQ) são fármacos utilizados no tratamento de malária e artrite reumatoide, e quando administrados em associação, podem reduzir a carga viral e bloquear a tempestade de citocinas provocada pelo SARS-CoV-2. Porém, é importante avaliar a cardiotoxicidade (síndrome de QT prolongado e cardiomiopatias) da HCQ em casos de uso prolongado em pacientes com disfunções renal ou hepática ou pacientes imunossuprimidos. Essa toxicidade pode ser, rapidamente letal e o tratamento intensivo deve ser iniciado imediatamente (De Clercq \& $\mathrm{Li}, 2016$ ).

A HCQ pode aumentar o $\mathrm{pH}$ intracelular e inibir a atividade lisossomial em células apresentadoras de antígenos, reduzindo a ativação de células $\mathrm{T}$, a diferenciação e a expressão de proteínas coestimuladoras e citocinas produzidas por células T e B. Pode também alterar o pH dos endossomos, interrompendo a ligação de receptores toll-like e suprimindo o ligante de RNA. No citoplasma, interfere na interação do DNA e síntese de ácidos nucleicos virais, atenuando a resposta próinflamatória e a geração de citocinas. Portanto, o fármaco pode inibir a replicação do SARS-CoV-2 pela inibição da hiperativação do sistema imunológico desencadeada pelo vírus e, assim, reduzir a progressão e gravidade da doença (Geamănu et al., 2014).

O possível mecanismo de ação da CQ que justificaria sua provável atividade antiviral é a inibição da replicação do vírus pela glicosilação terminal da enzima conversora de angiotensina 2, produzida pelos vasos pulmonares. Este fármaco inibiria a ligação vírus - receptor. Outra possibilidade é pelo aumento do pH endossômico, inibindo a infecção viral (Rosa e Santos, 2020).

O mecanismo de sinergismo da Azitromicina, que pode potencializar a ação da HCQ ainda não foi elucidado (Das, 2011).

No Brasil, a terapêutica utilizando a HCQ e CQ foi fortemente sugerida como prevenção à COVID-19. No entanto, em 2021, a OMS e a OPAS concluíram que estes fármacos não possuem eficácia na prevenção, nem no tratamento contra a COVID-19 e alertou que o seu uso pode provocar efeitos adversos graves e irreversíveis. Especialistas do Grupo de Desenvolvimento de Diretrizes da OMS declararam "forte recomendação" contra o seu uso no combate ao vírus e sugeriram que os financiadores e pesquisadores devem reconsiderar o início ou continuação das experiências, concluindo 
que a associação de HCQ e CQ não são prioridades de pesquisa e que os recursos devem ser direcionados para avaliar outras drogas no tratamento da COVID-19 (OPAS, 2021b).

Os ensaios clínicos e estudos multicêntricos conduzidos por Chen et al., 2020; Mitjà et al.,2020; Tang et al.,2020; Gautret et al. (2020), evidenciaram que a utilização de HCQ / CQ é ineficaz e com potenciais efeitos deletérios ao sistema cardiovascular, além de aumentar o tempo hospitalização e o risco de progressão à ventilação mecânica, podendo ocasionar a morte dos pacientes. Os eventos adversos graves observados são triplicados em comparação ao placebo.

A Artemisinina e seus derivados são antimaláricos e também possuem propriedades antivirais consideráveis, reduzindo a proliferação do vírus da hepatite $\mathrm{B}$, vírus da hepatite $\mathrm{C}$ e vírus da imunodeficiência humana (Romero, Paeshuyse, Obeid, Jung et al., 2005). Além disso, podem reduzir a secreção de citocinas pró-inflamatórias derivadas dos macrófagos, particularmente de fator de necrose tumoral. No entanto, é provável que a Artemisinina tenha um potencial terapêutico imunossupressor em processos inflamatórias persistentes (Varga et al., 2020).

A Piperaquina é uma droga que substituiu a CQ como agente de primeira linha para o tratamento da malária, desde 1978, e foi administrado como profilático na década de 1980. Portanto, a associação dos antimaláricos ArtemisininaPiperaquina pode apresentar eficácia terapêutica na redução do risco de morte em pacientes com COVID-19 (Hou, Shakir \& Yao, 2016).

Em um ensaio clínico realizado na China, em 2020, envolvendo 41 pacientes hospitalizados, portadores da COVID19 leve a moderada verificou-se que a associação de Artemisinina-Piperaquina reduziu tempo de permanência do vírus no organismo e apresentaram uma melhora pulmonar significativa. Porém, resultados clínicos demonstraram que pode ocorrer, em alguns pacientes, prolongamento de intervalos de QT (tempo que os ventrículos levam para contrair e repolarizar), sendo então recomendado o monitoramento cuidadoso destas alterações o tratamento (Li et al., 2020).

\subsection{Agente Antinematódico + associação}

A Ivermectina é um fármaco seguro e eficaz para o tratamento de diferentes tipos de infecções parasitárias em humanos a mais de 30 anos e encontra-se na lista de medicamentos essenciais da OMS para estas finalidades (Pandey et al., 2020).

O estudo realizado por Caly et al. (2020) para avaliar a atividade antiviral do fármaco, demonstrou que após 48 horas da administração de $5 \mu \mathrm{M}$ de Ivermectina em células Vero/hsLAM infectadas com SARS-CoV-2, houve uma redução de aproximadamente 5000 vezes do RNA viral em relação as amostras controle. A partir deste trabalho, outro estudo demonstrou que a concentração inibitória média (IC50; $2 \mu \mathrm{M}$ ) era 35 vezes maior que a concentração plasmática máxima (Cmax) após a administração da dose aprovada de Ivermectina. Desde então, diversos ensaios clínicos foram realizados para avaliar a ação antiviral da Ivermectina frente a COVID-19.

Em março de 2021, a OMS declarou que o fármaco apenas deveria ser utilizado no tratamento da COVID-19 em ensaios clínicos e com ambiente controlado. As evidências sobre seu uso clínico ainda são inconclusivas, e, portanto, o fármaco não deve ser utilizado no tratamento de pacientes que não apresentam um quadro de agravamento da doença. A organização incluiu esta recomendação nas suas diretrizes de tratamento da COVID-19 (WHO, 2021c).

Ensaios clínicos realizados nos EUA e Turquia revelaram que a Ivermectina proporcionou a melhora clínica e dos parâmetros laboratoriais e diminuição das taxas de mortalidade, especialmente em pacientes com agravamento do quadro pulmonar grave. Deve ser considerado como um fármaco alternativo a ser utilizado no tratamento da COVID-19 ou como uma opção adicional aos protocolos existentes (Hajter et al, 2020; Hosseini et al., 2020).

Em um ensaio randomizado conduzido por Mahmud et al. (2020), foi observado que a Ivermectina e a Doxiciclina foram coadministradas com justificativa de provável sinergismo, podendo aumentar a probabilidade de eficácia no tratamento 
da doença, em pacientes com sintomas leves a moderados da COVID-19. Não foram observadas interações medicamentosas conhecidas portanto, nenhuma alteração da dosagem do medicamento foi necessária no estudo. Os pacientes recuperaram-se mais rápido do que aqueles que receberam placebo, apresentaram-se menos propensos a progredir para uma doença grave. Porém, pesquisas adicionais sobre a segurança e a eficácia desta associação são necessárias.

\subsection{Agentes contra amebíase e outras doenças protozoárias}

Originalmente desenvolvida e comercializada como fármaco anti-helmíntico, a Nitazoxanida foi posteriormente identificada como a primeira droga antiviral de amplo espectro da classe e foi reaproveitada para o tratamento da influenza A e B. O mecanismo de ação deste fármaco envolve a inibição da replicação de uma ampla gama de outros vírus de RNA e DNA, incluindo vírus parainfluenza, coronavírus, rotavírus, norovírus, hepatite $\mathrm{B}$, hepatite $\mathrm{C}$, dengue, febre amarela, vírus da encefalite japonesa e vírus da imunodeficiência humana em ensaios de cultura de células. Os ensaios clínicos indicaram um papel potencial para os tiazolídeos (metabólito circulante ativo de nitazoxanida, no tratamento de gastroenterite por rotavírus e norovírus e hepatite B crônica e hepatite C crônica (Rossignol, 2014).

A Nitazoxanida é aprovada pela ANVISA apenas para o tratamento de gastroenterites virais provocadas por rotavírus ou norovírus, helmintíases, amebíase, giardíase, criptosporidíase, blastocistose, balantidíase e isosporíase. Estudos tem avaliado sua atividade antiviral demonstrando um possível efeito da Nitazoxanida no bloqueio da maturação da hemaglutinina viral na fase pós-tradução (Rocco, 2020). Desta forma, ocorre a supressão de citocinas pró- inflamatória, como a interleucina 6 e inibição da proteína $\mathrm{N}$ viral. Portanto, o mecanismo de ação desta droga poderia apresentar possível atividade sobre o coronavírus. (Rakedzon et al., 2021).

Em um estudo de caso conduzido por Meneses et al. (2020), a administração precoce do fármaco demonstrou efetividade na recuperação clínica dos pacientes, inclusive em pacientes graves e gestantes, sem apresentar efeitos indesejáveis para os bebês. Porém, no Brasil, o fármaco não foi aprovado pela ANVISA especificamente para o tratamento da COVID-19 e os pesquisadores e especialistas não reconhecem e não recomendam seu uso no tratamento precoce da doença.

\subsection{Bloqueador do Receptor de Angiotensina II}

Estudos recentes sugerem que pacientes portadores do SARS-CoV-2 apresentam elevação da concentração de angiotensina II, aumentando a permeabilidade pulmonar e, consequentemente, a elevação da patogenicidade da COVID-19. Sendo assim, bloqueadores do receptor de angiotensina II podem ser opções terapêuticas para esta doença (Liu et al., 2020).

Em ensaio clínico realizado com 34 pacientes hospitalizados com insuficiência respiratória relacionada a COVID-19, e administrados $50 \mathrm{mg}$ como dose alvo de Losartan, foram obtidos resultados seguros na redução do comprometimento respiratório agudo relacionado a COVID-19 (Bengston et al., 2020).

\subsection{Agentes antitrombóticos}

Pacientes acometidos pelo SARS-CoV-2 podem apresentam risco aumentado de tromboembolismo venoso. Embora não haja nenhuma grande série de casos publicados até agora, há relatos de parâmetros anormais de coagulação em pacientes hospitalizados com a COVID-19 grave (Kochi et al., 2020).

A ação anticoagulante e anti-inflamatória dos agentes antitrombóticos minimiza o risco de sepse e regula as citocinas pró-inflamatórias. Outros estudos indicam que os anticoagulantes podem aumentar os níveis de antitrombina III (AT-III), responsável pela neutralização da trombina por meio da inibição dos fatores de coagulação, que reduzem os eventos relacionados a eventos trombóticos. Um dos principais agentes é a Heparina, que possui propriedades anticoagulante, antiinflamatória, imunomoduladora e protetora (Thachil, 2020). 
Outro fármaco é a Enoxaparina, que é uma heparina alterada, de baixo peso molecular apresenta algumas vantagens em relação à heparina não fracionada, como os esquemas de administração mais simples, relação dose-resposta mais confiável e menor incidência de sangramento e de trombocitopenia. É amplamente utilizada no tratamento e na profilaxia do tromboembolismo (Lemos et al., 2020).

Em ensaios clínicos realizados com pacientes hospitalizados e tratados em hospital com Heparina e Enoxaparina, os resultados obtidos foram associados a uma redução da taxa de mortalidade, particularmente em pacientes graves e naqueles com forte ativação de coagulação, porém, ainda não está claro se o uso destes agentes é uma intervenção eficaz a todos pacientes portadores da COVID-19 ou deve ser limitado a condições específicas ou categorias de pacientes e quais doses devem ser administradas ( Di Castelnuovo et al., 2020; Lemos et al., 2020).

\subsection{Antidepressivo}

A Fluvoxamina é um inibidor seletivo de recaptação da serotonina, com propriedades de ligação aos receptores sigma-1 $(\sigma 1)$, que possuem várias funções celulares, incluindo a regulação da produção de citocinas. O fármaco é um dos primeiros lançados mundialmente para o tratamento da depressão, porém tem sido considerado mais para o tratamento do transtorno obsessivo-compulsivo e ansiedade (Sukhatme et al., 2020). Em estudo clínico, a Fluvoxamina foi administrada como tratamento precoce em pacientes com a forma leve da doença e apresentou eficácia associada à redução na deterioração clínica. As vantagens deste fármaco para o tratamento da doença incluem sua segurança, ampla disponibilidade, baixo custo e administração oral. Portanto, pode causar interações medicamentosas, principalmente por meio da inibição dos citocromos P450 1A2 e 2C19. Alguns pacientes podem apresentar pneumonia e sintomas gastrointestinais (como náuseas e vômitos). Ao reduzir a inflamação, a Fluvoxamina pode prevenir uma resposta imune hiperativa em pacientes com COVID-19, podendo reduzir o risco de ocorrência de doenças graves e morte (Lenze et al., 2020).

\subsection{Vasodilatador Periférico}

A Pentoxifilina é um inibidor não específico das fosfodiesterases e funciona como um agente hemorreológico, favorecendo a circulação e oxigenação sanguínea e exerce efeitos únicos na modulação imunológica, inflamação e estresse oxidativo. Exerce múltiplos efeitos imunomoduladores benéficos em estados de hiper inflamação. No entanto, o mecanismo de ação exato ainda permanece indefinido e seus efeitos clínicos não podem ser previstos com segurança (Kreth et al., 2010).

Os achados do estudo clínico de Maldonado et al. (2020), realizado em pacientes com quadros moderados e graves da COVID-19, demonstraram que a Pentoxifilina pode ser benéfica, com segurança comprovada, disponibilidade e nenhum risco de imunossupressão. O tratamento foi associado a um aumento de 64,25\% na contagem de linfócitos e uma diminuição de 29,61\% na Lactato Desidrogenase sérica (LDH), que são biomarcadores correlacionados com a gravidade da doença. Embora uma tendência de redução de dias de internação, mortalidade e proporção de pacientes que requerem intubação tenha sido observada, nenhuma diferença estatisticamente significativa foi encontrada para esses parâmetros.

\subsection{Expectorante / Mucolítico}

A atividade inibidora do Cloridrato de Bromexina em relação a protease TMPRSS2 o torna um fármaco eficiente quando administrado precocemente, reduzindo as taxas de admissões em UTI, intubação, ventilação mecânica e de mortalidade, além de ser um medicamento muito barato, acessível, seguro. No entanto, seu mecanismo de ação exato contra a infecção por SARS-CoV-2 precisa ser elucidado (Ansarin et al., 2020; Li et al., 2020). 


\subsection{Imunoestimulante}

Os interferons tipo I (IFN-I; IFN $\alpha$ e IFN $\beta$ ) funcionam de maneira autócrina e parácrina para induzir a expressão de vários genes estimulados por interferon (ISGs) que conferem atividades antivirais às células hospedeiras (Lee \& Shin, 2020).

Em ensaio clínico randomizado conduzido por Davoudi Monfared et al. (2020), a eficácia e segurança do IFN $\beta$-1a foram avaliadas em pacientes com COVID-19 grave. Embora o Interferon $\beta$-1a não tenha alterado o tempo de resposta clínica, aumentou significativamente a taxa de alta hospitalar e reduziu a taxa de mortalidade. A taxa de sobrevivência melhorada foi significativa quando os pacientes receberam IFN $\beta$-1a na fase inicial da doença. Os efeitos adversos do IFN $\beta$-1a relatados foram problemas neuropsiquiátricos e reações de hipersensibilidade, porém foram toleráveis e resolvidos durante o período de acompanhamento.

\subsection{Imunomoduladores}

A terapia com anticorpos monoclonais tem como base a produção de uma resposta imune para um único epítopo (ou determinante antigênico), oriunda de um único linfócito B. Geralmente o anticorpo monoclonal neutraliza o sítio de ligação do antígeno à célula-alvo. Os anticorpos monoclonais são produzidos em laboratório pela fusão de um linfócito B, produtor do anticorpo desejado à uma célula de mieloma, formando o hibridoma que se multiplicará e produzirá grandes quantidades de anticorpo. Os anticorpos produzidos serão utilizados na terapia e chamados de monoclonais, pois se originam de clones de um único linfócito B (Manis, 2019).

O Anakinra é um antagonista do receptor da interleucina (IL) -1 que bloqueia a atividade das citocinas próinflamatórias IL-1 $\alpha$ e IL-1 $1 \beta$ e é utilizado no tratamento de doenças auto inflamatórias, como doença de Still do adulto, artrite idiopática juvenil e Febre Mediterrânea (Cavalli \& Dinarello, 2015).

Em ensaio clínico multicêntrico aberto (CORIMUNO-ANA-1), conduzido pela CORIMUNO-19, realizado na França com pacientes portadores de pneumonia leve a moderada, aguda grave infecção por síndrome respiratória coronavírus 2 , o fármaco não foi eficaz na redução da necessidade de ventilação não invasiva ou mecânica ou morte em pacientes com COVID19 e pneumonia leve a moderada. Mais estudos são necessários para avaliar a sua eficácia em outros grupos selecionados de pacientes mais grave e em outras doses (CORIMUNO-19 Collaborative group, 2021).

A atividade antiviral da Leflunomida está relacionada a inibição da enzima diidroorotato desidrogenase (DHODH), uma flavo-enzima que exerce função importante na biossíntese de nucleotídeos da enzima. Ao inibir a DHODH, o fármaco pode ser capaz de reduzir a eficácia da replicação do genoma viral do SARS-CoV-2 ao infectar células hospedeiras (Wang et al., 2020).

No Brasil, a Leflunomida é um medicamento que tem seu uso aprovado pela ANVISA para o tratamento da artrite reumatoide ativa (doença do sistema imunológico, autoimune, que causa inflamação das articulações) e da artrite psoriática ativa (doença que causa manchas vermelhas e escamosas na pele, além da inflamação nas articulações). Sua ação imunossupressora reduz os sinais e sintomas da inflamação e inibe a destruição das articulações, o que contribui para a melhora das funções físicas e de saúde relacionadas à qualidade de vida. O setor de Farmacovigilância da agência reguladora tem registrado, em seus bancos de dados, relatos de abortos e malformações congênitas associados ao uso do fármaco. No entanto, deve ser utilizado por mulheres grávidas ou que possam ficar grávidas durante o tratamento, pois o fármaco pode provocar malformações no feto, sendo que a gravidez deve ser evitada durante todo o tratamento e até dois anos após a sua interrupção, devido ao longo período de permanência do medicamento no organismo (ANVISA, 2021b).

Em ensaio clínico realizado na China, em 2020, com 10 pacientes diagnosticados laboratorialmente com COVID-19 moderada e opacidade pulmonar foram tratados com Leflunomida. Houve redução do tempo de eliminação viral mais curto do 
que os controles, redução significativa nos níveis de proteína $C$ reativa, indicando que a inflamação imunopatológica foi controlada e redução do tempo de hospitalização e nenhum efeito adverso foi relatado (Hu et al., 2021).

O Meplazumabe é um anti-CD147 IgG 2 humanizado, que pode prevenir eficazmente a infecção por SARS-CoV-2. Um ensaio clínico foi conduzido por Bian et al. (2020), para avaliar a segurança, tolerabilidade e farmacocinética. No entanto, os dados obtidos, apresentaram uma boa segurança e tolerância ao fármaco e sugerem que o mesmo pode acelerar a recuperação de pacientes com pneumonia por COVID-19 com um perfil de segurança favorável.

Em abril de 2021, a ANVISA aprovou o uso emergencial do REGN-CoV2 (associação dos anticorpos monoclonais Casirivimabe e Imdevimabe) para os casos leves e moderados da COVID-19, sem necessidade de suplementação de oxigênio, em pacientes ambulatoriais adultos e pediátricos. Estes anticorpos monoclonais são proteínas produzidas em laboratório, especificamente direcionadas contra a proteína Spike do SARS-CoV-2. Sua administração é realizada via intravenosa. Porém em julho de 2021, o FDA revisou a autorização de uso emergencial do REGN-CoV-2 para adicionar uma autorização de uso emergencial como profilaxia pós-exposição (prevenção) em indivíduos adultos e pediátricos que apresentam risco de progressão para a forma grave da COVID-19, incluindo a hospitalização ou morte (ANVISA, 2021c).

Pelo ensaio clínico conduzido por Weinreich et al. (2020) foi possível observar que REGN-CoV-2 reduziu a carga viral, com maior efeito em pacientes cuja resposta imune ainda não havia sido iniciada ou que apresentavam carga viral elevada no início do estudo. Da mesma forma, a eliminação do vírus foi correlacionada com melhores desfechos clínicos. Além disso, foi observada uma baixa incidência de eventos adversos graves ocorridos ou agravados durante o período de observação e de reações relacionadas com a perfusão ou de hipersensibilidade.

Em novembro de 2020, o FDA autorizou o uso emergencial de Bamlanivimabe, no tratamento da COVID-19 de intensidade leve a moderada em pacientes adultos e pediátricos não hospitalizados e que apresentem alto risco de progressão para a forma grave da doença ou hospitalização, incluindo pacientes com idade igual ou superior a 65 anos ou que tenham certas condições crônicas. É administrado via intravenosa, portanto, os pacientes devem ir até um hospital para sua administração. No entanto não está autorizado no caso de pacientes hospitalizados ou que necessitem de oxigenioterapia.

Os resultados apresentados pelo estudo clínico conduzido por Chen et al. (2020) foram positivos em relação a efetividade na redução da carga viral e da exposição antigênica e os eventos adversos relatos pelos pacientes mais frequentes foram leves, como os gastrointestinais e hipertensão.

Em julho de 2021, a OMS recomendou o uso de dois anticorpos monoclonais Tocilizumabe e Sarilumabe. O mecanismo de ação do Sarilumabe, assim como o Tocilizumabe, é a modulação da transdução de sinal através do bloqueio da ligação da IL-6 com seu receptor celular para tratar os casos graves de COVID-19, juntamente com corticosteroides, reduzindo a probabilidade do paciente ser intubado ou morrer.

Em ensaios clínicos, foi possível concluir que em pacientes hospitalizados com pneumonia grave por SARS-CoV-2, o fármaco demonstrou potencial efetividade na redução da taxa de mortalidade de pacientes com insuficiência respiratória hipoxêmica grave, da taxa de mortalidade, da probabilidade de progressão para o desfecho composto de ventilação mecânica ou morte e melhora dos desfechos clínicos. Porém nos pacientes com pneumonia moderada, o Tocilizumabe não reduziu o risco de piora clínica (Salama et al., Salvarani et al., S et al., Rajendram et al., 2020).

A associação dos anticorpos monoclonais Bamlanivimabe + Etesevimabe apresentou efetividade na recuperação da linfopenia quando administrados concomitantemente, no tratamento dos casos leves a moderados em adultos e pacientes pediátricos (12 anos de idade ou mais pesando pelo menos $40 \mathrm{~kg}$ ) que apresentam alto risco de progressão para grave, incluindo hospitalização ou morte. Os eventos adversos relatados foram leves, com mais frequência náuseas, diarreia e reações de hipersensibilidade imediata (Gottlieb et al., 2020). 
A ANVISA aprovou, em 2021 o uso emergencial da associação de dois anticorpos monoclonais citado anteriormente. A terapêutica é indicada para adultos e pacientes pediátricos (com 12 anos ou mais que pesem no mínimo 40 kg) que não necessitam de suplementação de oxigênio, com infecção por SARS-CoV-2 confirmada por exames laboratoriais, e que apresentam alto risco de progressão para a forma grave da doença, não sendo recomendada para pacientes graves porque podem estar associados a piora nos desfechos clínicos quando administrados em pacientes hospitalizados e que necessitam de suplementação de oxigênio de alto fluxo ou ventilação mecânica (ANVISA, 2021d).

No Brasil, o anticorpo monoclonal Regdanvimabe, é o quarto medicamento a ser autorizado pela agência em caráter experimental e temporário, de uso emergencial contra o SARS-CoV-2 e sua administração é via intramuscular e de uso restrito a hospitais. É um anticorpo monoclonal IgG1 humano recombinante produzido por meio da tecnologia de DNA recombinante em uma linha de células de mamíferos. Este medicamento impede que o vírus entre nas células humanas ao se ligar à proteína Spike do SARS-CoV-2. Quando se liga à esta proteína, a interação entre o vírus e o receptor celular é bloqueada e a capacidade do vírus de entrar nas células do corpo é reduzida. Isso pode ajudar seu corpo a resistir à infecção pelo vírus e pode ajudar a prevenir o agravamento da doença. O fármaco é indicado para o tratamento da COVID-19 leve a moderada em pacientes adultos, que não necessitam de suplementação de oxigênio, com infecção por SARS-CoV-2 confirmada por exames laboratoriais e que apresentam alto risco de progressão para a doença em sua forma mais grave. Também é contraindicado para mulheres grávidas, lactantes, mulheres que pretendem engravidar, devido à escassez de estudos sobre o impacto da medicação nestas populações (ANVISA, 2021e).

O Sotrovimabe é o quinto medicamento autorizado em caráter experimental e temporário pela ANVISA no tratamento da COVID-19 leve ou moderada, para uso emergencial em adultos e crianças acima dos 12 anos (que pesem no mínimo $40 \mathrm{~kg}$ ), que não necessitam de suplementação de oxigênio. O tratamento deve ser iniciado assim que possível, após o teste viral positivo para SARS-CoV-2 e dentro de 5 dias do início dos sintomas clínicos. Seu uso é restrito a hospitais, sob prescrição médica e sua venda é proibida ao comércio.

\subsection{Agente Antineoplásico}

O Ruxolitinibe é um inibidor da quinase associada ao Janus (JAK 1 /2), aprovado pela FDA para o tratamento da policitemia vera e mielofibrose. É também uma opção promissora no tratamento da doença do enxerto contra hospedeiro aguda refratária a esteroides após o transplante de células-tronco hematopoéticas alogênicas ou linfo-histiocitose hemofagocítica secundária , visando os efeitos deletérios da resposta inflamatória aberrante do hospedeiro.

Segundo ensaio clínico conduzido por Cao et al. (2020), embora nenhuma diferença estatística tenha sido observada, os pacientes tratados com Ruxolitinibe apresentaram uma melhora clínica significativamente mais rápida. A anemia foi o evento adverso mais comum, embora a maioria dos eventos de anemia tenha sido de gravidade leve a moderada. Os eventos adversos não hematológicos foram geralmente baixos com o tratamento a longo prazo. A melhora significativa na tomografia computadorizada de tórax, uma recuperação mais rápida da linfopenia e um perfil de efeito colateral favorável do fármaco foram encorajadores e informativos para estudos futuros para testar sua eficácia em uma população maior.

\subsection{Imunomodulador em associação}

Em um estudo multicêntrico, a associação do Tocilizumabe com os esteroides, administrados em pacientes graves não intubados durante as primeiras 48 horas, após o aparecimento de insuficiência respiratória, apresentou um benefício adicional na redução da taxa de mortalidade. Alguns eventos adversos graves foram relatados, incluindo hepatotoxicidade com aumento das enzimas hepáticas ou bilirrubina, trombocitopenia, tromboflebite superficial relacionada ao cateter, diarreia, cefaléia, alterações oculares e bacteremia (Ruiz-Antorán et al., 2020). 
Em um ensaio clínico, a associação do Tocilizumabe com o antiviral Favipiravir, melhorou significativamente a inflamação pulmonar e reduziu a taxa de mortalidade. Além disso, a terapia combinada também pode aliviar significativamente os sintomas clínicos e restabelecer os exames laboratoriais. Os efeitos colaterais foram geralmente leves e autolimitados. Um resultado inesperado foi que o nível de IL-6 não só não diminuiu, mas aumentou ainda mais após a administração de Tocilizumabe (Zhao et al., 2020).

Em ensaio clínico conduzido por Dastan et al. (2020), a associação de Interferon $\beta-1$, via subcutânea à terapia de Hidroxicloroquina + Lopinavir / Ritonavir apresentou efetividade na redução dos sintomas clínicos e a depuração virológica reduziu significativamente em 10 dias e nenhum evento adverso foi relatado.

\subsection{Imunoestimulante + Antivirais de ação direta}

A associação tripla do Interferon beta-1b injetável com o inibidor de protease oral Lopinavir-Ritonavir e o análogo de nucleosídeo oral Ribavirina, quando administrada até 7 dias após o início dos sintomas foi eficaz na supressão da eliminação do SARS-CoV-2, não apenas em um esfregaço nasofaríngeo, mas em todas as amostras clínicas, em comparação com a monoterapia de Lopinavir-Ritonavir. Além disso, reduziu a carga viral, melhorando os sintomas clínicos e reduzindo o tempo de hospitalização. Os eventos adversos relatados foram leves e autolimitados (Hung et al., 2020).

É possível que o mecanismo de ação dos interferons no corpo humano seja capaz de promover a resposta imune inata mediada pelo fármaco na infecção por SARS-CoV-2, o que pode ajudar a limitar a infecção e o agravamento dos sintomas em um estágio inicial da doença. Numa fase posterior, a resposta imune adaptativa pode eventualmente auxiliar na recuperação dos pacientes.

\subsection{Imunoglobulina e Associações}

A Imunoglobulina Intravenosa (IVIg) é um produto sanguíneo obtido de doadores saudáveis e contém imunoglobulina gama policlonal. Desde sua descoberta como um tratamento eficaz há 30 anos, tem sido administrado como terapia imunomoduladora em doenças autoimunes e inflamatórias, como púrpura trombocitopênica imune, doença de Kawasaki, polineuropatia desmielinizante inflamatória crônica e neuropatia motora multifocal (Galeotti et al., 2017).

Um ensaio duplo-cego randomizado controlado por placebo foi conduzido com cinquenta e nove pacientes com infecção grave por SARS-CoV-2 e que não responderam aos tratamentos iniciais. A Imunoglobulina Gama apresentou efetividade melhorando o resultado clínico e reduzindo significativamente a taxa de mortalidade. Devido ao seu alto custo, deve ser considerado em pacientes com envolvimento pulmonar maior que 30\%, na tomografia computadorizada de pulmão, em pacientes em que a dispneia não melhora com o tratamento padrão, aqueles com saturação de O2 persistente abaixo de $90 \%$ e aqueles que desenvolvem agravamento de envolvimento pulmonar em tomografias computadorizadas de pulmão em série, especialmente em adultos jovens (Gharebaghi et al., 2020).

Os dados obtidos no ensaio clínico randomizado conduzido por Tabarsi et al. (2020), não suportam os efeitos benéficos do uso de IVIg em associação com HCQ e Lopinavir/Ritonavir em pacientes graves, uma vez que a taxa de mortalidade, alterações radiográficas e a necessidade de ventilação mecânica não apresentaram melhora significativa. No entanto, o tempo de internação na UTI e de hospitalização podem se a IVIg for administrada precocemente.

\subsection{Vitamina em Associação}

A vitamina C ou Ácido Ascórbico, é um antioxidante solúvel em água, que possui funções importantes no organismo, especialmente nas funções das células imunológicas. Alguns estudos relatam que a vitamina $\mathrm{C}$ pode ser eficaz no tratamento de infecções bacterianas e virais, inibindo a multiplicação dos vírus. Evidências recentes destacaram que a suplementação 
nutricional pode desempenhar um papel de suporte em pacientes com COVID-19. A administração de doses diárias maiores que as recomendadas de nutrientes, como vitaminas D, C, E, zinco e ácidos graxos ômega-3, pode ter um efeito benéfico, reduzindo potencialmente a carga viral de SARS-CoV-2 e o tempo de hospitalização (Gombart et al., 2020).

Segundo a ANVISA, o uso de vitamina C aumentou mais de 100\% durante a pandemia por coronavírus, porém seu uso requer atenção em pacientes em terapia anticoagulante concomitante; dieta restrita de sódio; diabetes; cálculos renais recorrentes e pacientes submetidos a exames de sangue oculto nas fezes.

Um ensaio clínico aberto, randomizado e controlado foi conduzido em pacientes com infecção grave por COVID19. O grupo controle recebeu Lopinavir / Ritonavir e Hidroxicloroquina e o grupo caso recebeu o antioxidante (6 g por dia) adicionado ao mesmo esquema. Porém, a associação proposta de Vitamina C intravenosa + Lopinavir / Ritonavir e Hidroxicloroquina não apresentou eficácia terapêutica contra o SARS-CoV-2. Porém a não apresentou eficácia terapêutica contra o SARS-CoV-2, nem mesmo na prevenção da doença (Jamali et al., 2020).

\subsection{Plasma Convalescente}

O plasma é a parte líquida do sangue, onde estão contidos os anticorpos. O objetivo do tratamento com plasma convalescente é transferir ao paciente, de maneira passiva, um quantitativo de anticorpos suficiente para combater o vírus. É obtido por meio de doação voluntária de plasma por aferese (separação dos componentes do sangue por centrifugação, por meio de um equipamento automatizado) ou de plasma por meio de doação de sangue total de pessoas que já foram contaminadas pelo SARS-CoV-2 e que, portanto, já possuem anticorpos (Piechotta et al., 2020).

Embora estudos observacionais tenham demonstrado consistentemente que o plasma convalescente possui perfil de segurança adequado em pacientes com COVID-19, os ensaios clínicos, demonstraram que em pacientes graves, a terapêutica não resultou em uma redução significativa no tempo de melhora clínica e também não reduziu a taxa de mortalidade nem melhorou outros resultados clínicos (Li et al., 2020; Schwartz et al., 2020; Kurtz et al., 2020; Simonovich et al., 2020). Nos casos leves a moderados, não foi associado a uma redução na progressão para a forma grave da doença e alguns eventos adversos foram relatados pelos pacientes, como erupções cutâneas, reação transfusional alérgica não severa definitiva, reação transfusional febril não hemolítica não severa, falta de ar, cianose e dispneia grave (Libster et al., 2020). Porém, sua administração precoce, em alto título, em idosos com infecção moderada reduziu significativamente a progressão da COVID19 (Agarwal et al.,2020; Libster et al., 2020; RECOVERY Collaborative Group, 2021; Salazar et al.,2020).

No Brasil, embora os ensaios clínicos e usos experimentais com plasma convalescente não sejam passíveis de aprovação prévia pela ANVISA, a Agência orienta fortemente a realização de ensaios clínicos controlados (ANVISA, 2021f).

\section{Conclusão}

Os fármacos e suas associações em estudo não demonstraram eficácia terapêutica específica para o tratamento da COVID-19; entretanto, os ensaios clínicos indicaram melhora nos sintomas clínicos dos pacientes, redução do tempo de internamento hospitalar e redução da taxa de mortalidade. Foi observado também que alguns fármacos apresentaram reações adversas graves (efeitos hepatotóxicos, reações de hipersensibilidade, entre outros), interferindo diretamente na segurança dos pacientes, podendo levá-los à morte.

Há vários estudos clínicos em andamento em diferentes centros de pesquisa, onde os resultados obtidos darão direcionamento para a terapia da COVID-19. Entretanto, novos estudos com a utilização de fármacos já existentes no mercado farmacêutico e outros em estudos pré-clínicos são necessários para o tratamento definitivo da COVID-19, observando-se sempre a eficácia terapêutica e a segurança do paciente. 


\section{Referências}

Abdelnabi, R., Foo, C., Jonghe, S., Maes, P., Weynand, B., \& Neyts, J. (2021). Molnupiravir Inhibits Replication of the Emerging SARS-CoV-2 Variants of Concern in a Hamster Infection Model. The Journal of Diseases, 224, 749 - 753. https://doi.org/10.1093/infdis/jiab361

Agarwal, A., Mukherjee, A., Kumar, G., Chatterjee, P., Bhatnagar, T., Malhotra, P., \& PLACID Trial Collaborators (2020). Convalescent plasma in the management of moderate covid-19 in adults in India: open label phase II multicentre randomised controlled trial. Clinical research, 371 , m3939. https://doi.org/10.1136/bmj.m3939

Agência Nacional de Vigilância Sanitária (Anvisa, 2021 a). Combate à pandemia. Anvisa autoriza uso emergencial de novo medicamento para Covid-19. https://www.gov.br/anvisa/pt-br/assuntos/noticias-anvisa/2021/anvisa-autoriza-uso-emergencial-de-novo-medicamento-para-covid-19

Agência Nacional de Vigilância Sanitária (Anvisa, 2021 b). Leflunomida: Risco de aborto e malformações. http://antigo.anvisa.gov.br/informacoestecnicas13?p_p_id=101_INSTANCE_WvKKx2fhdjM2\&p_p_col_id=column-1\&p_p_col_pos=1\&p_p_col_count=2\&_101_INSTANCE_Wv $\quad$ KKx 2 fhdj M2_groupId=33868\&_101_INSTANCE_WvKKx2fhdjM2_urlTitle=leflunomida-risco-de-aborto-e-malformacoes-nos-fetos-e-associacao-com-o-surgimentoou-reativacao-de-casos-de-tuberculose-e-outras-infeccoe-1\&_101_INSTANCE_WvKKx2fhdjM2_struts_action=\%2Fasset_pu blisher\%2Fview_conte nt \&_101_I NST A NCE_WvKKx2fhdjM2_assetEntryId=2891036\&_101_INSTANCE_WvKKx2fhdjM2_type=content

Agência Nacional de Vigilância Sanitária (ANVISA,2021c). Aprovação REGN-CoV-2. https://www.gov.br/anvisa/pt-br/assuntos/noticiasanvisa/2021/aprovado-uso-emergencial-de-anticorpos-para-tratamento-de-covid-19/apresentacao-regn-cov2-ggmed.pdf/view

Agência Nacional de Vigilância Sanitária (ANVISA,2021d). Anvisa aprova o uso emergencial de mais uma associação de anticorpos contra o novo coronavírus. Banlanivimabe e Etesevimabe são indicados no tratamento das formas leve a moderada da COVID. https://www.gov.br/anvisa/ptbr/assuntos/noticias-anvisa/2021/anvisa-aprova-o-uso-emergencial-de-mais-uma-associacao-de-anticorpos-contra-o-novo-coronavirus $\begin{aligned} & \text { Agência Nacional de } \\ & \text { br/assuntos/paf/coronavirus/medicamentos/regkirona }\end{aligned}$ Vigilância Sanitária
(ANVISA,2021e).

Agência Nacional de Vigilância Sanitária (ANVISA,2021f). Atualizada nota técnica sobre uso de plasma de doador convalescente. https://www.gov.br/anvisa/pt-br/assuntos/noticias-anvisa/2021/atualizada-nota-tecnica-sobre-uso-de-plasma-de-doador-convalescente

Amirian, E. S., \& Levy, J. K. (2020). Current knowledge about the antivirals Remdesivir (GS-5734) and GS-441524 as therapeutic options for coronaviruses. One Health, 9, 100 - 128. https://doi.org/10.1016/j.onehlt.2020.100128.

Angus, D. C., Derde, L., Al-Beidh, F., Annane, D., Arabi, Y., Beane, A., van Bentum-Puijk, W., Berry, L., Bhimani, Z., Bonten, M., Bradbury, C., Brunkhorst, F., Buxton, M., Buzgau, A., Cheng, A. C., de Jong, M., Detry, M., Estcourt, L., Fitzgerald, M., Goossens, H., \& Summers, C. (2020). Effect of Hydrocortisone on Mortality and Organ Support in Patients with Severe COVID-19. Corticosteroid Domain Randomized Clinical Trial. Jama, 324, 13171329.http://doi:10.1001/jama.2020.17022.

Ansarin, K., Tolouian, R., Ardalan, M., Taghizadieh, A., Varshochi, M., Teimouri, S., Vaezi, T., Valizadeh, H., Saleh, P., Safiri, S., \& Chapman, K. R. (2020). Effect of bromhexine on clinical outcomes and mortality in COVID-19 patients: A randomized clinical trial. BioImpacts, 10, 209-215. doi: $10.34172 /$ bi.2020.27

Aquino, M. E., Silveira, H. I., Pescarini, M. J., Aquino, R., Souça, A. J., \& Rocha, S. A. (2020). Social distancing measures to control the COVID-19 pandemic: potential impacts and challenges in brazil. Scielo Brazil. ciência e saúde coletiva, 25 (supl 1). https://doi.org/10.1590/1413-81232020256.1.10502020.

Bai, Y., Yao, L., Wei, T., Tian, F., Jin, D.-Y., Chen, L., \& Wang, M. (2020). Presumed Asymptomatic Carrier Transmission of COVID-19. Jama, 323 (14), 1406-1407. doi: $10.1001 /$ jama.2020.2565

Barlow, A., Landolf, K.M, Barlow, B., Yeung, S., Heavner, J., \& Claassen C. (2020). Review of Emerging Pharmacotherapy for the Treatment of Coronavirus Disease 2019, Pharmacotherapy,40(5), 416-437. http://doi: 10.1002/phar.2398

Bengtson, C. D., Montgomery, R. N., Nazir, U., Satterwhite, L., Kim, M. D., Bahr, N. C., Castro, M., Baumlin, N., \& Salathe, M. (2021). An Open Label Trial to Assess Safety of Losartan for Treating Worsening Respiratory Illness in COVID-19. Frontiers in Medicine, 8 , article 630209. https://doi.org/10.3389/fmed.2021.630209

Bian, H., Zheng, Z., Wei, D., Zhang, Z., Kang, W., \& Hao, C. (2020). Meplazumab treats COVID-19 pneumonia: an open-labelled, concurrent controlled addon clinical trial. medRxiv. doi: https://doi.org/10.1101/2020.03.21.20040691

Blaising, J., Polyak, S. J \& Pécheur, E. I. (2014). Arbidol as a broad-spectrum antiviral: an update. Antiviral Research,107, 84-94. https://doi.org/10.1016/j.antiviral.2014.04.006

Bronte, V., Ugel, S., Tinazzi, E., Vella, A., Sanctis, F., \& Cané, S. (2020). Baricitinib restrains the immune dysregulation in patients with severe COVID-19. The Journal of Clinical Investigation, 130, 6409-6416._http://doi: 10.1172 / JCI141772

Butler, C. C., Yu, L. M., Dorward, J., Gbinigie, O., Hayward, G., Saville, B. R., Van Becke, O., Berry, N., Detry, M. A., Saunders, C., Fitzgerald, M., Harris, V., Djukanovic, R., Gadola, S., Kirkpatrick, J., De Lusignan, S., Ogburn, E., Evans, P. H., Thomas, N., \& Patel, M. G. Principal trial collaborative group (2021). Doxycycline for community treatment of suspected covid-19 in people at high risk of adverse outcomes in the uk (principle): a randomised, controlled, open-label, adaptive platform trial. The Lancet, 9, 1010-1020. https://doi.org/10.1016/s2213-2600(21)00310-6

Caly, 1., Druce, J., Catton, M., \& Jans, W., (2020). The FDA approved drug ivermectin inhibits the replication of Sars-Cov-2 in vitro. Antiviral Research, 178 , 104787. https://doi.org/10.1016/j.antiviral.2020.104787

Cao, Y., Wei, J., Zou, L., Jiang, T., Wang, G., Chen, L., Huang, L., Meng, F., Huang, L., Wang, N., Zhou, X., Luo, H., Mao, Z., Chen, X., Xie, J., Liu, J., Cheng, H., Zhao, J., Huang, G., Wang, W., \& Zhou, J. (2020). Ruxolitinib in treatment of severe coronavirus disease 2019 (COVID-19): A multicenter, singleblind, randomized controlled trial. The Journal of Allergy and Clinical Immunology, 146, 137-146.e3. http://doi: 10.1016 / j.jaci.2020.05.019 
Cavalli, G., \& Dinarello, C. A. (2015). Treating rheumatological diseases and co-morbidities with interleukin-1 blocking therapies. Rheumatology. Oxford England, 54, 2134-2144. https://doi.org/10.1093/rheumatology/kev269

Chan, J. F., Chan, K. H., Kao, R. Y., To, K. K., Zheng, B. J., Li, C. P., Li, P. T., Dai, J., Mok, F. K., Chen, H., Hayden, F. G., \& Yuen, K. Y. (2013). Broadspectrum antivirals for the emerging Middle East respiratory syndrome coronavirus. The Journal of Infection,67(6), 606-616. https://doi.org/10.1016/j.jinf.2013.09.029.

Chan, W., Yuan, S., Kok, K., To, W., Chu, H., Yang, J., \& Poon, R. W. (2020). A familial cluster of pneumonia associated with the 2019 novel coronavirus indicating person-to-person transmission: a study of a family cluster. The Lancet, 395, 514-523. https://doi.org/10.1016/ S0140-6736(20)30154-9

Chen, C. P., Lin, Y. C., Chen, T. C., Tseng, T. Y., Wong, H. L., Kuo, C. Y., Lin, W. P., Huang, S. R., Wang, W. Y., Liao, J. H., Liao, C. S., Hung, Y. P., Lin, T. H., Chang, T. Y., Hsiao, C. F., Huang, Y. W., Chung, W. S., Cheng, C. Y., Cheng, S. H., \& Taiwan HCQ Study Group (2020). A multicenter, randomized, open-label, controlled trial to evaluate the efficacy and tolerability of Hydroxychloroquine and a retrospective study in adult patients with mild to moderate coronavirus disease 2019 (COVID-19). PloS one, 15(12), e0242763. https://doi.org/10.1371/journal.pone.0242763.

Chen, P., Nirula, A., Heller, B., Gottlieb, R. L., Boscia, J., Morris, J., Huhn, G., Cardona, J., Mocherla, B., Stosor, V., Shawa, I., Adams, A. C., Van Naarden, J., Custer, K. L., Shen, L., Durante, M., Oakley, G., Schade, A. E., Sabo, J., Patel, D. R., BLAZE-1 Investigators (2021). SARS-CoV-2 Neutralizing Antibody LY-CoV555 in Outpatients with Covid-19. The New England Journal of Medicine, 384(3), 229-237.

Chiba, S. (2020). Effect of early oseltamivir on outpatients without hypoxia with suspected Covid-19. Wiener klinische wochenschrift, 133,292 - 297. http://doi: 10.1007 / s00508-020-01780-0

Cohen J. (2020). Antibodies may curb pandemic before vaccines. Science, 369, 752-753. https://doi.org/10.1126/science.369.6505.752

CORIMUNO-19 Collaborative group (2021). Effect of Anakinra versus usual care in adults in hospital with COVID-19 and mild-to-moderate pneumonia (CORIMUNO-ANA-1): a randomised controlled trial. The Lancet. Respiratory Medicine, 9(3), 295-304. http:// doi: 10.1016 / S2213-2600 (20) 30556-7

Corral-Gudino, L., Bahamonde, A., Arnaiz-Revillas, F., Gómez-Barquero, J., Abadía-Otero, J., García-Ibarbia, C., Mora, V., Cerezo-Hernández, A., Hernández, J. L., López-Muñíz, G., Hernández-Blanco, F., Cifrián, J. M., Olmos, J. M., Carrascosa, M., Nieto, L., Fariñas, M. C., Riancho, J. A., \& Glucocovid investigators (2021). Methylprednisolone in adults hospitalized with COVID-19 pneumonia: An open-label randomized trial (GLUCOCOVID). Wiener klinische Wochenschrift, 133(7-8), 303-311. https://doi.org/10.1007/s00508-020-01805-8

Dabbous, H. M., Abd-Elsalam, S., El-Sayed, M. H., Sherief, A. F., Ebeid, F., El Ghafar, M., Soliman, S., Elbahnasawy, M., Badawi, R., \& Tageldin, M. A. (2021). Efficacy of Favipiravir in COVID-19 treatment: a multi-center randomized study. Archives of Virology, 16, 949-954. https://doi.org/10.1007/s00705021-04956-9

Das B. K. (2011). Azithromycin induced hepatocellular toxicity and hepatic encephalopathy in asymptomatic dilated cardiomyopathy. Indian Journal of Pharmacology, 43, 736-737. https://doi.org/10.4103/0253-7613.89841

Dastan, F., Nadji, S. A., Saffaei, A., Marjani, M., Moniri, A., Jamaati, H., Hashemian, S. M., Baghaei, P., Abedini, A., Varahram, M., Yousefian, S., \& Tabarsi, P. (2020). Subcutaneous administration of Interferon beta-1a for COVID-19: A non-controlled prospective trial. International Immunopharmacology, 85, 106688. https://doi.org/10.1016/j.intimp.2020.106688.

Davoodi, L., Abedi, S., Salehifar, E., Alizadeh-Navaei, R., Rouhanizadeh, H., Khorasani, G., \& Hosseinimehr, SJ (2020). Febuxostate therapy in ambulatory patients with suspected COVID-19: a clinical trial. International Journal of Clinical Practice, 74 (11), e13600.

Davoudi-Monfared, E., Rahmani, H., Khalili, H., Hajiabdolbaghi, M., Salehi, M., Abbasian, L., Kazemzadeh, H., \& Yekaninejad, M. S. (2020). A Randomized Clinical Trial of the Efficacy and Safety of Interferon $\beta-1 \mathrm{a}$ in Treatment of Severe COVID-19. Antimicrobial agents and chemotherapy, 64, e01061-20. https://doi.org/10.1128/AAC.01061-20

De Clercq, E., \& Li, G. (2016). Approved Antiviral Drugs over the Past 50 Years. Clinical Microbiology Reviews, 29, 695-747.

Deftereos, S. G., Giannopoulos, G., Vrachatis, D. A., Siasos, G. D., Giovani, S. G., Gargalianos, P., Metallidis, S., Cianos, G., Baltagiannis, S., Panagopoulos, P., Dolianitis, K., Randou, E., Syrigos, K., Kotanidou, A., Koulouris, N. G., Milionis, H., Sipsas, N., Gogos, C., Tsoukalas, G., Olímpios, C. D., GRECCO-19 investigators (2020). Effect of Colchicine vs Standard Care on Cardiac and Inflammatory Biomarkers and Clinical Outcomes in Patients Hospitalized with Coronavirus Disease 2019: The GRECCO-19 Randomized Clinical Trial. JAMA, 3, e2013136. https://doi.org/10.1001/jamanetworkopen.2020.13136

Dequin, P. F., Heming, N., Meziani, F., Plantefève, G., Voiriot, G., Badié, J., François, B., Aubron, C., Ricard, J. D., Ehrmann, S., Jouan, Y., Guillon, A., Leclerc, M., Coffre, C., Bourgoin, H., Lengellé, C., Caille-Fénérol, C., Tavernier, E., Zohar, S., Giraudeau, B. (2020). Effect of Hydrocortisone on 21-Day Mortality or Respiratory Support Among Critically Ill Patients with COVID-19: A Randomized Clinical Trial. JAMA, 324, 1298-1306.

Dhar, S. K., K, V., Damodar, S., Gujar, S., \& Das, M. (2021). IL-6 and IL-10 as predictors of disease severity in COVID-19 patients: results from metaanalysis and regression. Heliyon, 7, e06155. https://doi.org/10.1016/j.heliyon.2021.e06155

Di Castelnuovo, A., Costanzo, S., Antinori, A., Berselli, N., Blandi, L., Bonaccio, M., Cauda, R., Guaraldi, G., Menicanti, L., Mennuni, M., Parruti, G., Patti, G., Santilli, F., Signorelli, C., Vergori, A., Abete, P., Ageno, W., Agodi, A., Agostoni, P., Aiello, L., Iacoviello, L. (2021). Heparin in COVID-19 Patients Is Associated with Reduced In-Hospital Mortality: The Multicenter Italian CORIST Study. Thrombosis and Haemostasis, 121(8), 1054-1065. https://doi.org/10.1055/a-1347-6070

Dubert, M., Visseaux, B., Isernia, V., Bouadma, L., Deconinck, L., Patrier, J., Wicky, P. H., Le Pluart, D., Kramer, L., Rioux, C., Le Hingrat, Q., HouhouFidouh, N., Yazdanpanah, Y., Ghosn, J., \& Lescure, F. X. (2020). Case report study of the first five COVID-19 patients treated with remdesivir in France. International journal of infectious diseases : IJID : official publication of the International Society for Infectious Diseases, 98, 290-293. https://doi.org/10.1016/j.ijid.2020.06.093

Fahmi, A. N., Shehatou, G. S., Shebl, A. M., \& Salem, H. A. (2016). Febuxostat protects rats against lipopolysaccharide-induced lung inflammation in a dosedependent manner. Naunyn-Schmiedeberg's archives of pharmacology, 389(3), 269-278. https://doi.org/10.1007/s00210-015-1202-6 
Fehr, A. R., \& Perlman, S. (2015). Coronaviruses: an overview of their replication and pathogenesis. Methods in molecular biology, 1282, 1-23. https://doi.org/10.1007/978-1-4939-2438-7_1.

Galeotti, C., Kaveri, S. V., \& Bayry, J. (2017). IVIG-mediated effector functions in autoimmune and inflammatory diseases. International Immunology, 29(11), 491-498. https://doi.org/10.1093/intimm/dxx039

Gautret, P., Lagier, J. C., Parola, P., Hoang, V. T., Meddeb, L., Mailhe, M., Doudier, B., Courjon, J., Giordanengo, V., Vieira, V. E., Tissot Dupont, H., Honoré, S., Colson, P., Chabrière, E., La Scola, B., Rolain, J. M., Brouqui, P., \& Raoult, D. (2020). Hydroxychloroquine and azithromycin as a treatment of COVID-19: results of an open-label non-randomized clinical trial. International Journal of Antimicrobial Agents, 56(1), 105949. https://doi.org/10.1016/j.ijantimicag.2020.105949

Geamănu Pancă, A., Popa-Cherecheanu, A., Marinescu, B., Geamănu, CD, \& Voinea, LM (2014). Toxicidade retinal associada à exposição crônica à hidroxicloroquina e seu rastreio ocular. Journal of medicine and life , 7 (3), 322-326.

Gharebaghi, N., Nejadrahim, R., Mousavi, S. J., Sadat-Ebrahimi, S. R., \& Hajizadeh, R. (2020). The use of intravenous immunoglobulin gamma for the treatment of severe coronavirus disease 2019: a randomized placebo-controlled double-blind clinical trial. BMC Infectious Diseases, $20(1)$, 786. https://doi.org/10.1186/s12879-020-05507-4

Goldman, J. D., Lye, D., Hui, D. S., Marks, K. M., Bruno, R., Montejano, R., Spinner, C. D., Galli, M., Ahn, M. Y., Nahass, R. G., Chen, Y. S., SenGupta, D., Hyland, R. H., Osinusi, A. O., Cao, H., Blair, C., Wei, X., Gaggar, A., Brainard, D. M., Towner, W. J., (2021). Remdesivir for 5 or 10 Days in Patients with Severe Covid-19. The New England Journal of Medicine, 383(19), 1827-1837. https://doi.org/10.1056/NEJMoa2015301.

Gombart A.F, Pierre A., Maggini S. (2020). Working in harmony to reduce the risk of infection. Nutrients.; 12 (1): 236.

Gottlieb, R. L., Nirula, A., Chen, P., Boscia, J., Heller, B., Morris, J., Huhn, G., Cardona, J., Mocherla, B., Stosor, V., Shawa, I., Kumar, P., Adams, A. C., Van Naarden, J., Custer, K. L., Durante, M., Oakley, G., Schade, A. E., Holzer, T. R., Ebert, P. J., Skovronsky, D. M. (2021). Effect of Bamlanivimabe as Monotherapy or in Combination with Etesevimabe on Viral Load in Patients with Mild to Moderate COVID-19: A Randomized Clinical Trial. JAMA, 325(7), $632-644$.

Hasan, M. J., Rabbani, R., Anam, A. M., Huq, S., Polash, M., Nessa, S., \& Bachar, S. C. (2021). Impact of high dose of Baricitinib in severe COVID-19 pneumonia: a prospective cohort study in Bangladesh. BMC Infectious Diseases, 21(1), 427. https://doi.org/10.1186/s12879-021-06119-2

Hinks, T., Cureton, L., Knight, R., Wang, A., Cane, J. L., Barber, V. S., Black, J., Dutton, S. J., Melhorn, J., Jabeen, M., Moss, P., Garlapati, R., Baron, T., Johnson, G., Cantle, F., Clarke, D., Elkhodair, S., Underwood, J., Lasserson, D., Pavord, I. D., Richards, D. (2021). Azithromycin versus standard care in patients with mild-to-moderate COVID-19 (ATOMIC2): an open-label, randomised trial. The Lancet. Respiratory Medicine, 9(10), 1130-1140.

Hosseini, F. S., Malektojari, A., Ghazizadeh, S., Hassaniazad, M., Davoodian, P., Dadvand, H., Nikpoor, A. R., Nikoofal-Sahlabadi, S., Kahoori, S., Sepandi, M., Hassanipour, S., \& Fathalipour, M. (2021). The efficacy and safety of Ivermectin in patients with mild and moderate COVID-19: A structured summary of a study protocol for a randomized controlled trial. Trials, 22(1), 4. https://doi.org/10.1186/s13063-020-04988-7

Hou, L., \& Huang, H. (2016). Immune suppressive properties of artemisinin family drugs. Pharmacology \& Therapeutics, 166, 123-127. https://doi.org/10.1016/j.pharmthera.2016.07.002.

Hu, B., Guo, H., Zhou, P., \& Shi, Z. L. (2021). Characteristics of SARS-CoV-2 and Covid-19. Nature Reviews, 19(3), 141-154. https://doi.org/10.1038/s41579-020-00459-7.

Hu, K., Wang, M., Zhao, Y., Zhang, Y., Wang, T., Zheng, Z., Li, X., Zeng, S., Zhao, D., Li, H., Xu, K., \& Lan, K. (2020). A Small-Scale Medication of Leflunomide as a Treatment of COVID-19 in an Open-Label Blank-Controlled Clinical Trial. Virologica Sínica, 35(6), 725-733.

Huang, C., Wang, Y., Li, X., Ren, L., Zhao, J., Hu, Y., Zhang, L., Fan, G., Xu, J., Gu, X., Cheng, Z., Yu, T., Xia, J., Wei, Y., Wu, W., Xie, X., Yin, W., Li, H., Liu, M., Xiao, Y., Cao, B. (2020). Clinical features of patients infected with 2019 novel coronavirus in Wuhan, China. The Lancet , 395(10223), 497-506. https://doi.org/10.1016/ S0140-6736(20)30183-5

Hung, I. F., Lung, K. C., Tso, E. Y., Liu, R., Chung, T. W., Chu, M. Y., Ng, Y. Y., Lo, J., Chan, J., Tam, A. R., Shum, H. P., Chan, V., Wu, A. K., Sin, K. M., Leung, W. S., Law, W. L., Lung, D. C., Sin, S., Yeung, P., Yip, C. C., Yuen, K. Y. (2020). Triple combination of Interferon beta-1b, Lopinavir-Ritonavir, and Ribavirin in the treatment of patients admitted to hospital with COVID-19: an open-label, randomised, phase 2 trial. The Lancet, 395(10238), $1695-1704$.

Irie, K., Nakagawa, A., Fujita, H., Tamura, R., Eto, M., Ikesue, H., Muroi, N., Tomii, K., \& Hashida, T. (2020). Pharmacokinetics of Favipiravir in Critically Ill Patients With COVID-19. Clinical and Translational Science, 13(5), 880-885.

JamaliMoghadamSiahkali, S., Zarezade, B., Koolaji, S., SeyedAlinaghi, S., Zendehdel, A., Tabarestani, M., Sekhavati Moghadam, E., Abbasian, L., Dehghan Manshadi, S. A., Salehi, M., Hasannezhad, M., Ghaderkhani, S., Meidani, M., Salahshour, F., Jafari, F., Manafi, N., \& Ghiasvand, F. (2021). Safety and effectiveness of high-dose vitamin C in patients with COVID-19: a randomized open-label clinical trial. European Journal of Medical Research, 26(1), 20. https://doi.org/10.1186/s40001-021-00490-1

Jung M, Schinazi R..F.(1994). Synthesis, and in vitro activity of human immunodeficiency virus of Artemisinin-related trioxanes (qinghaosu). Bioorg Med Chem Lett, 4, 931-934. http://doi: 10.1016 / S0960-894X (01) 80266-3.

Kalil A.C, Patterson T.F, Mehta A.K, Tomashek K. et al. (2020). Baricitinib plus Remdesivir for Hospitalized Adults with Covid-19.The New England Journal of Medicine,384 ed.9, 795 - 807. http://doi: 10.1056/NEJMoa2031994.

Khalili, H., Nourian, A., Ahmadinejad, Z., Emadi Kouchak, H., Jafari, S., Dehghan Manshadi, S. A., Rasolinejad, M., \& Kebriaeezadeh, A. (2020). Efficacy and safety of Sofosbuvir/ Ledipasvir in treatment of patients with COVID-19; A randomized clinical trial. Acta bio-medica : Atenei Parmensis, 91(4), e2020102. 
Khamis, F., Al Naabi, H., Al Lawati, A., Ambusaidi, Z., Al Sharji, M., Al Barwani, U., Pandak, N., Al Balushi, Z., Al Bahrani, M., Al Salmi, I., \& AlZakwani, I. (2021). Randomized controlled open label trial on the use of Favipiravir combined with inhaled Interferon beta-1b in hospitalized patients with moderate to severe COVID-19 pneumonia. The International Society for Infectious Diseases, 102, 538-543. https://doi.org/10.1016/j.ijid.2020.11.008

Kochi, A. N., Tagliari, A. P., Forleo, G. B., Fassini, G. M., \& Tondo, C. (2020). Cardiac and arrhythmic complications in patients with COVID-19. Journal of cardiovascular electrophysiology, 31(5), 1003-1008. https://doi.org/10.1111/jce.14479.

Kurtz, P., Righy, C., Gadelha, M, Bozza, F., Effect of Convalescent Plasma in Critically Ill Patients With COVID-19: An Observational Study. Frontiers in Medicine, 8, article 630982. https://doi.org/10.3389/fmed.2021.630982

Lai, C. C., Liu, Y. H., Wang, C. Y., Wang, Y. H., Hsueh, S. C., Yen, M. Y., Ko, W. C., \& Hsueh, P. R. (2020). Asymptomatic carrier state, acute respiratory disease, and pneumonia due to severe acute respiratory syndrome coronavirus 2 (SARS-CoV-2): Facts and myths. Journal of microbiology, immunology, and infection, 53(3), 404-412. https://doi.org/10.1016/j.jmii.2020.02.012

Lan, X., Shao, C., Zeng, X., Wu, Z., \& Xu, Y. (2021). Lopinavir-Ritonavir alone or combined with Arbidol in the treatment of 73 hospitalized patients with COVID-19: A pilot retrospective study. International journal of clinical pharmacology and therapeutics, 59(5), 378-385. https://doi.org/10.5414/CP203861

Lee, J. S., \& Shin, E. C. (2020). The type I interferon response in COVID-19: implications for treatment. Nature Reviews, $20(10)$, 585-586. https://doi.org/10.1038/s41577-020-00429-3

Lemos, A.C., Do Espirito Santo, D., Salvetti, M., Girilio, R.N., Agra, L., Pazin, A. (2020) Therapeutic versus prophylactic anticoagulation for severe COVID19: A randomized phase II clinical trial. Thrombosis Research, 196, 359-366. https://www.thrombosisresearch.com/article/S0049-3848(20)30530-2/fulltext

Leneva, I., Kartashova, N., Poromov, A., Gracheva, A., Korchevaya, E., Glubokova, E., Borisova, O., Shtro, A., Loginova, S., Shchukina, V., Khamitov, R., \& Faizuloev, E. (2021). Antiviral Activity of Umifenovir In Vitro against a Broad Spectrum of Coronaviruses, Including the Novel SARS-CoV-2 Virus. Viruses, 13(8), 1665. https://doi.org/10.3390/v13081665

Lenze, E. J., Mattar, C., Zorumski, C. F., Stevens, A., Schweiger, J., Nicol, G. E., Miller, J. P., Yang, L., Yingling, M., Avidan, M. S., \& Reiersen, A. M. (2020). Fluvoxamine vs Placebo and Clinical Deterioration in Outpatients with Symptomatic COVID-19: A Randomized Clinical Trial. JAMA, 324(22), 22922300

Li, T., Sun, L., Zhang, W., Zheng, C., Jiang, C., Chen, M., Chen, D., Dai, Z., Bao, S., \& Shen, X. (2020). Bromhexine Hydrochloride Tablets for the Treatment of Moderate COVID-19: An Open-Label Randomized Controlled Pilot Study. Clinical and Translational Science, 13(6), 1096-1102. https://doi.org/10.1111/cts. 12881

Li, G., Yuan, M., Li, H., Deng, C., Wang, Q., Tang, Y., Zhang, H., Yu, W., Xu, Q., Zou, Y., Yuan, Y., Guo, J., Jin, C., Guan, X., Xie, F., \& Song, J. (2021). Safety and efficacy of artemisinin-piperaquine for treatment of COVID-19: an open-label, non-randomised and controlled trial. International journal of antimicrobial agents, 57(1), 106216

Li, L., Zhang, W., Hu, Y., Tong, X., Zheng, S., Yang, J., Kong, Y., Ren, L., Wei, Q., Mei, H., Hu, C., Tao, C., Yang, R., Wang, J., Yu, Y., Guo, Y., Wu, X., $\mathrm{Xu}, \mathrm{Z}$., Zeng, L., Xiong, N., ... Liu, Z. (2020). Effect of Convalescent Plasma Therapy on Time to Clinical Improvement in Patients with Severe and Lifethreatening COVID-19: A Randomized Clinical Trial. JAMA, 324(5), 460-470.

Libster, R., Pérez Marc, G., Wappner, D., Coviello, S., Bianchi, A., Braem, V., Esteban, I., Caballero, M. T., Wood, C., Berrueta, M., Rondan, A., Lescano, G., Cruz, P., Ritou, Y., Fernández Viña, V., Álvarez Paggi, D., Esperante, S., Ferreti, A., Ofman, G., Ciganda, Á.(2021). Early High-Titer Plasma Therapy to Prevent Severe Covid-19 in Older Adults. The New England journal of medicine, 384(7), 610-618.

Liu, Y., Yang, Y., Zhang, C., Huang, F., Wang, F., Yuan, J., Wang, Z., Li, J., Li, J., Feng, C., Zhang, Z., Wang, L., Peng, L., Chen, L., Qin, Y., Zhao, D., Tan, S., Yin, L., Xu, J., Zhou, C.,Liu, L. (2020). Clinical and biochemical indexes from 2019-nCoV infected patients linked to viral loads and lung injury. Science China. Life Sciences, 63(3), 364-374.

Lu, R., Zhao, X., Li, J., Niu, P., Yang, B., Wu, H., Zhu, N. (2020). Genomic characterisation and epidemiology of 2019 novel coronavirus: implications for virus origins and receptor binding. The Lancet, 395 (10224), 565-574.

Mahmud, R., Rahman, M. M., Alam, I., Ahmed, K., Kabir, A., Sayeed, S., Rassel, M. A., Monayem, F. B., Islam, M. S., Islam, M. M., Barshan, A. D., Hoque, M. M., Mallik, M. U., Yusuf, M. A., \& Hossain, M. Z. (2021). Ivermectin in combination with doxycycline for treating COVID-19 symptoms: a randomized trial. The Journal of international medical research, 49(5), 1 - 14._https://doi.org/10.1177/03000605211013550

Manis, J.P. (2019). Overview of therapeutic monoclonal antibodies. Up To Date. https://www.uptodate.com/contents/overview-of-therapeutic-monoclonalantibodies

Meneses Calderón, J., Figueroa Flores, M., Paniagua Coria, L., Briones Garduño, J. C., Meneses Figueroa, J., Vargas Contretas, M. J., De la Cruz Ávila, L., Díaz Meza, S., Ramírez Chacón, R., Padmanabhan, S., \& Mendieta Zerón, H. (2020). Nitazoxanide against COVID-19 in three explorative scenarios. Journal of infection in developing countries, 14(9), 982-986.

Mitjà, O., Corbacho-Monné, M., Ubals, M., Tebe, C., Peñafiel, J., Tobias, A., Ballana, E., Alemany, A., Riera-Martí, N., Pérez, C. A., Suñer, C., Laporte, P., Admella, P., Mitjà, J., Clua, M., Bertran, L., Sarquella, M., Gavilán, S., Ara, J., Argimon, J. M.,BCN PEP-CoV-2 RESEARCH GROUP (2020). Hydroxychloroquine for Early Treatment of Adults with Mild Covid-19: A Randomized-Controlled Trial. Clinical infectious diseases : an official publication of the Infectious Diseases Society of America. https://doi.org/10.1093/cid/ciaa1009

Elgohary, M. A-S., Medhat Hasan, E., Ibrahim, A. A., Abdelsalam, M. F. A., Abdel-Rahman, R. Z., Zaki, A. I., Elaatar, M. B. (2021). Efficacy of Sofosbuvir plus Ledipasvir in Egyptian patients with COVID-19 compared to standard treatment: Randomized controlled trial. https://doi.org/10.1101/2021.05.19.21257429.

Murai, Y., Kawasuji, H., Takegoshi, Y., Kaneda, M., Kimoto, K., Ueno, A., Miyajima, Y., Kawago, K., Fukui, Y., Ogami, C., Sakamaki, I., Tsuji, Y., Morinaga, Y., \& Yamamoto, Y. (2021). A case of COVID-19 diagnosed with Favipiravir-induced drug fever based on a positive drug-induced lymphocyte stimulation test. International journal of infectious diseases , 106, 33-35. 
Nojomi, M., Yassin, Z., Keyvani, H., Makiani, M. J., Roham, M., Laali, A., Dehghan, N., Navaei, M., \& Ranjbar, M. (2020). Effect of Arbidol (Umifenovir) on COVID-19: a randomized controlled trial. BMC infectious diseases, 20(1), 954. https://doi.org/10.1186/s12879-020-05698-w

Obeid, S., Alen, J., Nguyen, V. H., Pham, V. C., Meuleman, P., Pannecouque, C., Le, T. N., Neyts, J., Dehaen, W., \& Paeshuyse, J. (2013). Artemisinin analogues as potent inhibitors of in vitro hepatitis $\mathrm{C}$ virus replication. PloS one, 8(12), e81783. https://doi.org/10.1371/journal.pone.0081783

Organização Mundial Da Saúde (OMS, 2021). Vacinas contra a COVID-19. https://www.paho.org/pt/vacinas-contra-covid-19

Organização Pan -Americana da Saúde (2020). OMS afirma que COVID-19 é agora caracterizada como pandemia. March 2020. https://www.paho.org/pt/news/11-3-2020-who-characterizes-covid-19-pandemic

Organização Pan -Americana da Saúde (2021 a). Folha informativa sobre a COVID-19. https://www.paho.org/pt/covid19

Organização Pan -Americana da Saúde $(2021$ b). Orientação Dinâmica da OMS. Medicamentos para prevenção da COVID-19. https://apps.who.int/iris/handle/10665/339877

Paeshuyse J, Coelmont L, Vliegen I, Hemel J Van, Vandenkerckhove J, Peys E. Hemin potentiates the anti-hepatitis C virus activity of the 28ntimalarial drug artemisinin. Biochem Biophys Res Commun. 2006; $348: 139-144$.

Pandey, S., Pathak, S. K., Pandey, A., Salunke, A. A., Chawla, J., Sharma, A., Sharma, S., Thivari, P., \& Ratna, H. (2020). Ivermectin in COVID-19: What do we know? Diabetes \& metabolic syndrome, 14(6), 1921-1922.

Pani, A., Lauriola, M., Romandini, A., \& Scaglione, F. (2020). Macrolídeos e infecções virais: enfoque na azitromicina na patologia de COVID-19. International Journal of Antimicrobial Agents, 56, Issue 2. https://doi.org/10.1016/j.ijantimicag.2020.106053

Pasquini, Z., Montalti, R., Temperoni, C., Canovari, B., Mancini, M., Tempesta, M. (2020). Effectiveness of Remdesivir in patients with Covid-19 under mechanical ventilation in an italian icu. journal of antimicrobial chemotherapy, volume 75 , issue 11,3359-3365.

Piechotta, V., Iannizzi, C., Chai, K.L, Valk, S.J., Kimber , C., Dorando, E., Monsef, I., Wood, E.M., Lamikanra, A.A., Roberts, D.J., McQuilten, Z., SoOsman, C., Estcourt, L.J, Skoetz, N.(2021) . Convalescent plasma or hyperimmune immunoglobulin for people with COVID-19: a living systematic review. Cochrane Database of Systematic Reviews, Issue 5. Art. No.: CD013600. http://doi: 10.1002/14651858.CD013600

Rajendram, P., Sacha, G. L., Mehkri, O., Wang, X., Han, X., Vachharajani, V., \& Duggal, A. (2021). Tocilizumab in Coronavirus Disease 2019-Related Critical Illness: A Propensity Matched Analysis. Critical care explorations, 3(1), e0327. https://doi.org/10.1097/CCE.0000000000000327

Rajter, J. C., Sherman, M. S., Fatteh, N., Vogel, F., Sacks, J., \& Rajter, J. J. (2021). Use of Ivermectin Is Associated with Lower Mortality in Hospitalized Patients with Coronavirus Disease 2019: The Ivermectin in COVID-19. Chest, 159(1), 85-92. https://doi.org/10.1016/j.chest.2020.10.009

Rakedzon, S., Neuberger, A., Domb, A. J., Petersiel, N., \& Schwartz, E. (2021). From hydroxychloroquine to ivermectin: what are the anti-viral properties of anti-parasitic drugs to combat SARS-CoV-2? Journal of travel medicine, 28(2), taab005. https://doi.org/10.1093/jtm/taab005.

RECOVERY Collaborative Group (2021). Convalescent plasma in patients admitted to hospital with COVID-19 : a randomised controlled, open-label, platform trial. The Lancet , 397(10289), 2049-2059. https://doi.org/10.1016/ S0140-6736(21)00897-7

Rocco, P., Silva, P. L., Cruz, F. F., Melo-Junior, M., Tierno, P., Moura, M. A., De Oliveira, L., Lima, C. C., Dos Santos, E. A., Junior, W. F., Fernandes, A., Franchini, K. G., Magri, E., de Moraes, N. F., Gonçalves, J., Carbonieri, M. N., Dos Santos, I. S., Paes, N. F., Maciel, P., Rocha, R. P.(2021). Early use of Nitazoxanide in mild COVID-19 disease: randomised, placebo-controlled trial. The European Respiratory Journal, 58(1), 2003725.

Romero, M.R., Efferth, T., Serrano, M.A., Castaño, B., Macias, R., Briz, O. (2015). Effect of Artemisinin / Artesunate as inhibitors of hepatitis B virus production in an "in vitro" replicative system". Antiviral Research., 68, 75-83. https://doi.org/10.1016/j.antiviral.2005.07.005

Rosa, S., \& Santos, W. C. (2020). Clinical trials on drug repositioning for COVID-19 treatment. Revista panamericana de salud publica. Pan American journal of Public Health, 44, e40. https://doi.org/10.26633/RPSP.2020.40

Rossignol J. F. (2014). Nitazoxanide: a first-in-class broad-spectrum antiviral agent. Antiviral research, 110, 94-103. https://doi.org/10.1016/j.antiviral.2014.07.014

Ruiz-Antorán, B., Sancho-López, A., Torres, F., Moreno-Torres, V., de Pablo-López, I., García-López, P., Abad-Santos, F., Rosso-Fernández, C. M., AldeaPerona, A., Montané, E., Aparicio-Hernández, R. M., Llop-Rius, R., Pedrós, C., Gijón, P., Hernández-Carballo, C., Pedrosa-Martínez, M. J., RodríguezJiménez, C., Prada-Ramallal, G., Cabrera-García, L., Aguilar-García, J. A.,.TOCICOV-study group (2021). Combination of Tocilizumab and Steroids to Improve Mortality in Patients with Severe COVID-19 Infection: A Spanish, Multicenter, Cohort Study. Infectious diseases and therapy, 10(1), $347-362$.

Salama, C., \& Mohan, S. V. (2021). Tocilizumab in Patients Hospitalized with Covid-19 Pneumonia. Reply. The New England journal of medicine, 384(15), $1473-1474$

Salazar, E., Perez, K. K., Ashraf, M., Chen, J., Castillo, B., Christensen, P. A., Eubank, T., Bernard, D. W., Eagar, T. N., Long, S. W., Subedi, S., Olsen, R. J., Leveque, C., Schwartz, M. R., Dey, M., Chavez-East, C., Rogers, J., Shehabeldin, A., Joseph, D., Williams, G., ... Musser, J. M. (2020). Treatment of Coronavirus Disease 2019 (COVID-19) Patients with Convalescent Plasma. The American journal of pathology, 190(8), 1680-1690.

Salvarani, C., Dolci, G., Massari, M., Merlo, D. F., Cavuto, S., Savoldi, L., Bruzzi, P., Boni, F., Braglia, L., Turrà, C., Ballerini, P. F., Sciascia, R., Zammarchi, L., Para, O., Scotton, P. G., Inojosa, W. O., Ravagnani, V., Salerno, N. D., Sainaghi, P. P., Brignone, A. R. (2021). Effect of Tocilizumab vs Standard Care on Clinical Worsening in Patients Hospitalized With COVID-19 Pneumonia: A Randomized Clinical Trial. JAMA internal medicine, 181(1), $24-31$.

Sekhavati, E., Jafari, F., SeyedAlinaghi, S., Jamalimoghadamsiahkali, S., Sadr, S., Tabarestani, M., Pirhayati, M., Zendehdel, A., Manafi, N., Hajiabdolbaghi, M., Ahmadinejad, Z., Kouchak, H. E., Jafari, S., Khalili, H., Salehi, M., Seifi, A., Golestan, F. S., \& Ghiasvand, F. (2020). Safety and effectiveness of azithromycin in patients with COVID-19: An open-label randomised trial. International journal of antimicrobial agents, 56(4), 106143. 
Shakir, L, Hussain, M., Javeed, A., Ashraf, M., Riaz, A. (2011). Artemisinins and immun system. Eur J Pharmacology, 668 : 6-14. http://doi: 10.1016 / j.ejphar.2011.06.044.

Shiraki, K., \& Daikoku, T. (2020). Favipiravir, an anti-influenza drug against life-threatening RNA virus infections. Pharmacology \& therapeutics, 209, 107512. https://doi.org/10.1016/j.pharmthera.2020.107512.

Simkin, J., Strange, T., Leblanc, N., \& Rivera, J. (2021). What is a cytokine storm, and should it matter to me? The Journal of the american academy of orthopedic surgeons, 29(7), 297-299. https://doi.org/10.5435/jaaos-d-20-00805

Simonovich, V. A., Burgos, D., Scibona, P., Beruto, M. V., Vallone, M. G., Vázquez, C., Savoy, N., Giunta, H., Pérez, G., Sánchez, M., Gamarnik, A. V., Ojeda, D. S., Santoro, D. M., Camino, P. J., Antelo, S., Rainero, K., Vidiella, P., Miyazaki, E. A., Cornistein, W., Trabadelo,O. A. (2021). A randomized trial of convalescent plasma in COVID-19 severe pneumonia. The New England Journal of Medicine, 384(7), 619-629

Strohbehn, G. W., Heiss, B. L., Rouhani, S. J., Trujillo, J. A., Yu, J., Kacew, A. J., Higgs, E. F., Bloodworth, J. C., Cabanov, A., Wright, R. C., Koziol, A., Weiss, A., Danahey, K., Karrison, T. G., Edens, C. C., Ventura, I. B., Pettit, N. N., Patel, B., Pisano, J., Strek, M. E., Reid, P. D. (2020). COVIDOSE: Lowdose tocilizumab in the treatment of Covid-19. MedRxiv, 2020.07.20.20157503. https://doi.org/10.1101/2020.07.20.20157503.

Sukhatme, V., Reiersen, A., Vayttaden, S., Sukhatme, V. (2020). Fluvoxamine: a review of its mechanism of action and its role in COVID-19. Frontiers in Pharmacology._https://doi.org/10.3389/fphar.2021.652688.

Tabarsi, P., Barati, S., Jamaati, H., Haseli, S., Marjani, M., Moniri, A., Abtahian, Z., Dastan, A., Yousefian, S., Eskandari, R., Saffaei, A., Monjazebi, F., Vahedi, A., \& Dastan, F. (2021). Evaluating the effects of Intravenous Immunoglobulin (IVIg) on the management of severe COVID-19 cases: A randomized controlled trial. International Immunopharmacology, 90, 107205.

Tang, W., Cao, Z., Han, M., Wang, Z., Chen, J., Sun, W., Wu, Y., Xiao, W., Liu, S., Chen, E., Chen, W., Wang, X., Yang, J., Lin, J., Zhao, Q., Yan, Y., Xie, Z., Li, D., Yang, Y., Liu, L., Xie, Q. (2020). Hydroxychloroquine in patients with mainly mild to moderate coronavirus disease 2019: open label, randomised controlled trial. $B M J, 369, \mathrm{~m} 1849$. https://doi.org/10.1136/bmj.m1849

Thachil, J., Tang, N., Gando, S., Falanga, A., Levi, M., Clark, C., Iba, T. \& Cattaneo, M. (2020). Type and dose of heparin in Covid-19: Reply. J Thromb Haemost, $18(8), 2063-4$.

Tomazini, B. M., Maia, I. S., Cavalcanti, A. B., Berwanger, O., Rosa, R. G., Veiga, V. C., Avezum, A., Lopes, R. D., Bueno, F. R., Silva, M., Baldassare, F. P., Costa, E., Moura, R., Honorato, M. O., Costa, A. N., Damiani, L. P., Lisboa, T., Kawano-Dourado, L., Zampieri, F. G., Olivato, G. B., Coalition COVID19 Brazil III Investigators (2020). Effect of Dexamethasone on Days Alive and Ventilator-Free in Patients with Moderate or Severe Acute Respiratory Distress Syndrome and COVID-19. JAMA, 324(13), 1307-1316. https://doi.org/10.1001/jama.2020.17021

Varga, Z., Flammer, A. J., Steiger, P., Haberecker, M., Andermatt, R., Zinkernagel, A. S., Mehra, M. R., Schuepbach, R. A., Ruschitzka, F., \& Moch, H. (2020). Endothelial cell infection and endotheliitis in COVID-19. The Lancet, 395(10234), 1417-1418. https://doi.org/10.1016/ S0140-6736(20)30937-5

Wang, M., Cao, R., Zhang, L., Yang, X., Liu, J., Xu, M., Xiao, G. (2020). Remdesivir and Chloroquine effectively inhibit the recently emerged novel coronavirus (2019-nCoV) in vitro. Cell Research, 30 (3), 269-271.

Wang, M., Zhao, Y., Hu, W., Zhao, D., Zhang, Y., Wang, T., Zheng, Z., Li, X., Zeng, S., Liu, Z., Lu, L., Wan, Z., \& Hu, K. (2020). Treatment of COVID-19 Patients with Prolonged Post-Symptomatic Viral Shedding with Leflunomide -- a Single-Center, Randomized, Controlled Clinical Trial. Clinical infectious diseases : an official publication of the Infectious Diseases Society of America, 1417. https://doi.org/10.1093/cid/ciaa1417

Weinreich, D. M., Sivapalasingam, S., Norton, T., Ali, S., Gao, H., Bhore, R., Musser, B. J., Soo, Y., Rofail, D., Im, J., Perry, C., Pan, C., Hosain, R., Mahmood, A., Davis, J. D., Turner, K. C., Hooper, A. T., Hamilton, J. D., Baum, A., Kyratsous, C. A. Trial Investigators (2021). REGN-COV2, a Neutralizing Antibody Cocktail, in Outpatients with Covid-19. The New England journal of medicine, 384(3), 238-251.

World Health Organization (2021a). WHO Coronavirus (COVID-19) Dashboard. Jun 2021. https://covid19.who.int/

WHO Collaborating Center of Drug Statistics Methodology (2021b). Lista ATC/DDD. https://www.whocc.no/atc_ddd_index/?code=L04AA37

World Health Organization (2021c). COVID-19 Manejo Clínico. https://iris.paho.org/handle/10665.2/53945?locale-attribute=pt

Yamazaki, S., Suzuki, T., Sayama, M., Nakada, T. A., Igari, H., \& Ishii, I. (2021). Suspected cholestatic liver injury induced by favipiravir in a patient with COVID-19. The Japan Society of Chemotherapy, 27(2), 390-392. https://doi.org/10.1016/j.jiac.2020.12.021

Yao, W., Wang, F., Wang, H. (2016). Immunomodulation of Artemisinin. Sci Bull, 61 : 1399-1406. http://doi: 10.1007 / s11434-016-1105-z.

Yates, P., Newman, S., Oshry, L., Glassman, R., Leone, A., Reichel, E. (2020). Doxycycline treatment of high-risk COVID-19-positive patients with comorbid pulmonary disease. http://doi: 10.1177/1753466620951053.

Ye, Q., Wang, B., \& Mao, J. (2020). The pathogenesis and treatment of the 'Cytokine Storm' in COVID-19. The Journal of infection, 80(6), 607-613. https://doi.org/10.1016/j.jinf.2020.03.037.

Yuen, K.S., Ye, Z.W., Fung, S.Y., Chan, C.P., \& Jin, D.Y. (2020). SARS-CoV-2 and COVID-19: the most important research questions. Cell \& Bioscience, 10 (1), 1-5. doi: http://dx.doi.org/10.5694/mja2.50577.

Zhang, L., Lin, D., Sun, X., Curth, U., Drosten, C., Sauerhering, L. (2020). Crystal structure of SARS-CoV-2 main protease provides a basis for design of improved $\alpha$-ketoamide inhibitors, 368 (6489), 409-412.

Zhang, W., Zhao, Y., Zhang, F., Wang, Q., Li, T., Liu, Z., Wang, J., Qin, Y., Zhang, X., Yan, X., Zeng, X., \& Zhang, S. (2020). The use of anti-inflammatory drugs in the treatment of people with severe coronavirus disease 2019 (COVID-19): The Perspectives of clinical immunologists from China. Clinical Immunology, 214, 108393. https://doi.org/10.1016/j.clim.2020.108393 
Research, Society and Development, v. 11, n. 1, e11611124445, 2021

(CC BY 4.0) | ISSN 2525-3409 | DOI: http://dx.doi.org/10.33448/rsd-v11i1.24445

Zhao, H., Zhu, Q., Zhang, C., Li, J., Wei, M., Qin, Y., Chen, G., Wang, K., Yu, J., Wu, Z., Chen, X., \& Wang, G. (2021). Tocilizumab combined with favipiravir in the treatment of COVID-19: A multicenter trial in a small sample size. Biomedicine \& Pharmacotherapy, 133 , 110825. https://doi.org/10.1016/j.biopha.2020.110825

Zhou, Q., Chen, V., Shannon, C. P., Wei, X. S., Xiang, X., Wang, X., Wang, Z. H., Tebbutt, S. J., Kollmann, T. R., \& Fish, E. N. (2020). Interferon- $\alpha 2 b$ treatment for COVID-19. Frontiers In Immunology, 11, 1061. https://doi.org/10.3389/fimmu.2020.01061 